\title{
Tools and Methods in Product Development to Reduce the Environmental Impact
}

\author{
A Master's Thesis submitted for the degree of \\ "Master of Science"
}

supervised by

Univ.Prof.Dr.Dr.mult.h.c Peter Kopacek

Franz Herbert Josef Kaltseis

0927532 


\section{Affidavit}

I, Franz Herbert Josef Kaltseis, hereby declare

1. that I am the sole author of the present Master Thesis, "Tools and Methods in Product Design Development to Reduce the Environmental Impact", eighty eight pages, bound, and that I have not used any source or tool other than those referenced or any other illicit aid or tool, and

2. that I have not prior to this date submitted this Master Thesis as an examination paper in any form in Austria or abroad.

Grieskirchen, _ 12.11.2010

Date

Signature 


\section{Table of Contents}

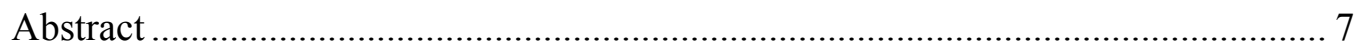

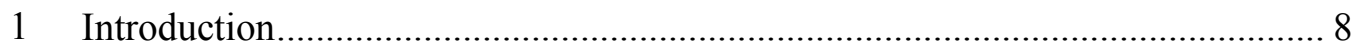

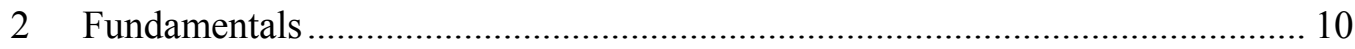

2.1 Factors for promoting environmental design practices ........................... 10

2.1.1 Competitive differentiation ...................................................... 11

2.1.2 Customer consciousness........................................................... 11

2.1.3 Governmental regulatory pressures............................................ 12

2.1.4 Profitability improvements ...................................................... 12

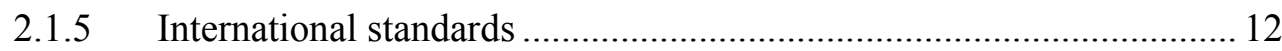

2.2 ECO Labels as a driver for environmental design practices ..................... 13

2.2.1 Type I ECO Labeling ............................................................... 13

2.2.2 Type II Self-declared Environmental Claim ................................... 14

2.2.3 Type III Environmental Product Declaration (EPD) ........................ 15

2.3 Different types of environmental labels in comparison ............................ 16

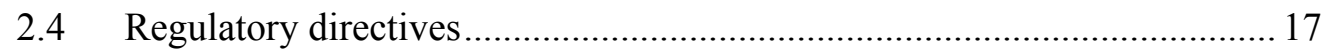

2.4.1 WEEE (Waste from Electrical and Electronic Equipment) ................ 17

2.4.2 RoHS (Reduction of Hazardous Substances).................................... 18

2.4.3 EuP (Energy using Products) …................................................ 18

2.4.4 REACH (Registration, Evaluation and Authorization of Chemicals) . 19 


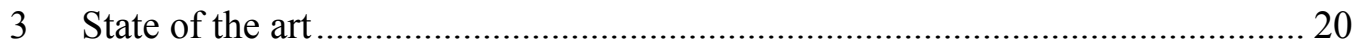

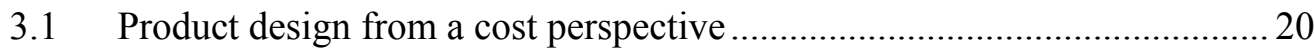

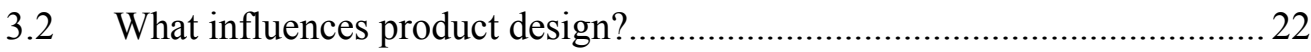

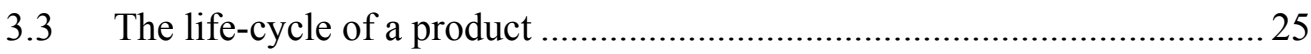

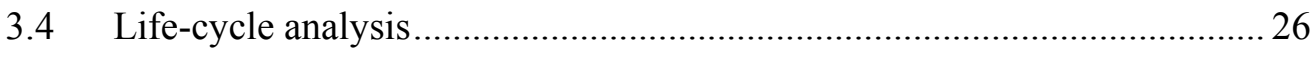

3.5 Life-Cycle Relationships for Recycling and Disposal ............................ 28

3.6 Defining the different types of environmental waste in manufacturing...... 30

3.7 Principles of Environmental Friendly design ............................................. 32

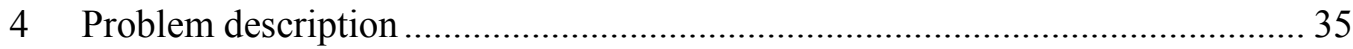

4.1 Challenges in product development ……............................................... 36

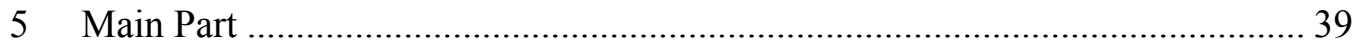

5.1 The development of design knowledge - Autodesk Digital Prototyping .... 39

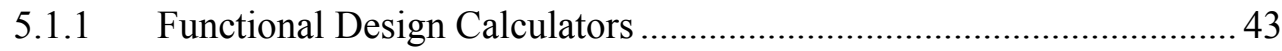

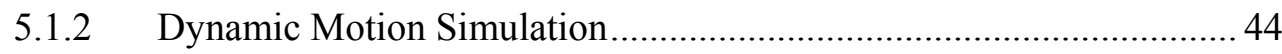

5.1.3 Assembly Linear Stress Simulation ................................................ 44

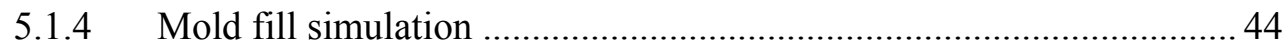

5.1.5 Fluid dynamics and heat transfer analysis ..................................... 45

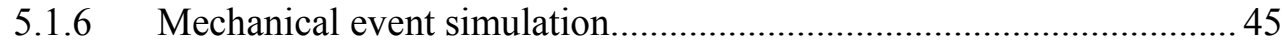

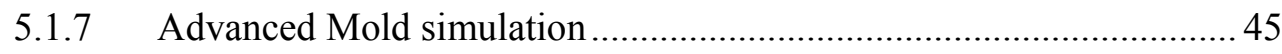

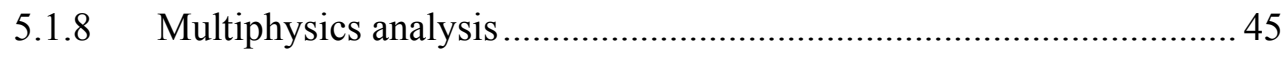

5.2 Designing environmental friendly plastic products.................................. 46

5.2.1 Exploring environmentally friendly materials ............................... 47

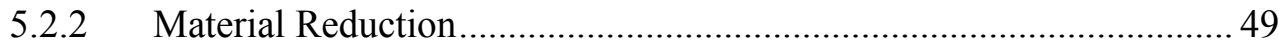


5.2.3 Thermoplastic Scrap Reduction ......................................................5 50

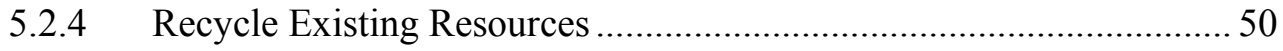

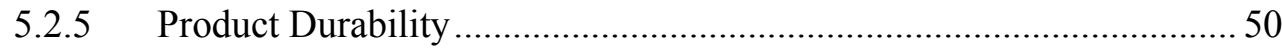

5.2.6 Energy consumption involved in the production process ................... 50

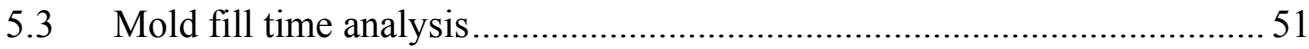

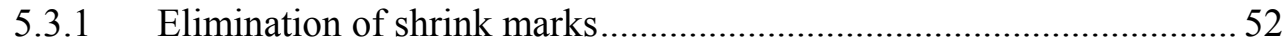

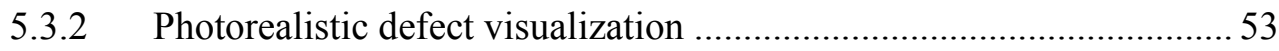

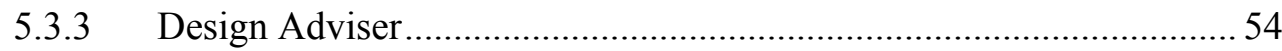

5.4 Real time feedback for plastic components design ................................ 55

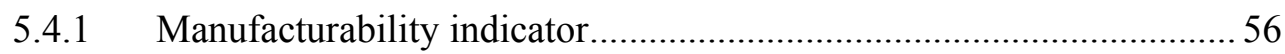

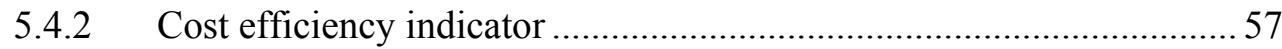

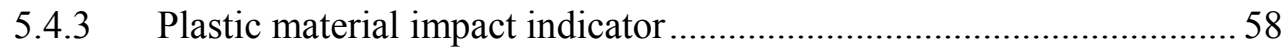

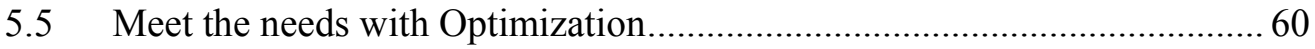

5.5.1 Optimization of multiple parameters ............................................. 61

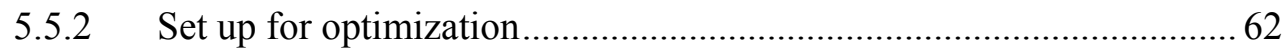

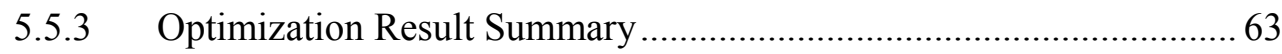

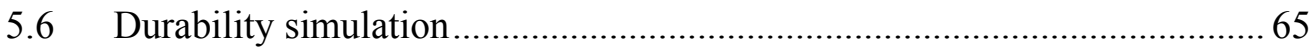

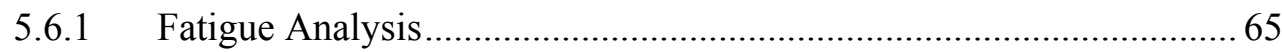

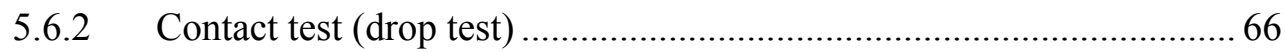

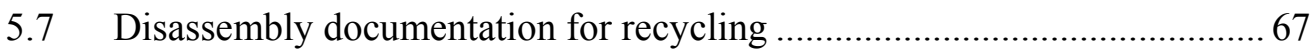

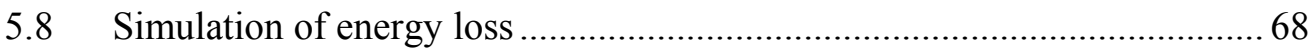

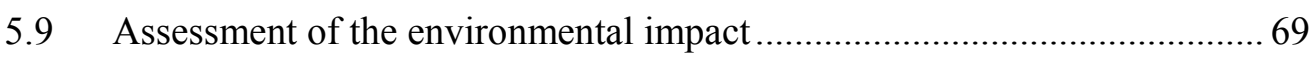

5.9.1 Lifecycle Analysis with Inventor ${ }^{\circledR}$ and Sustainable Minds ............... 69 
5.10 CAD/PLM Solution Suppliers and Sustainability Development ................ 71

5.10.1 PTC Environmental Compliance ….............................................. 72

5.10.2 Dassault Systemes Solidworks....................................................... 73

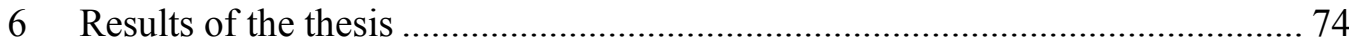

6.1.1 Potential Business Benefits ............................................................. 74

6.1.2 Adoption and Implementation of Software Tools............................. 75

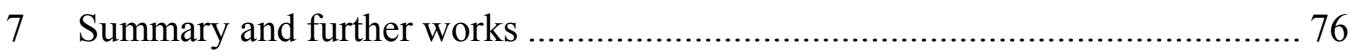

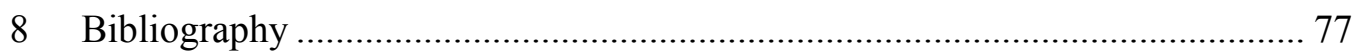

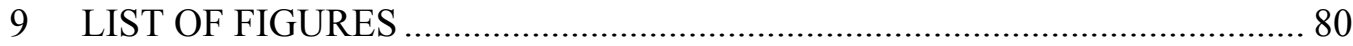

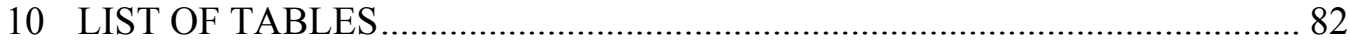

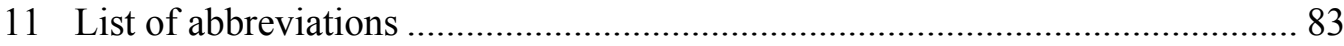

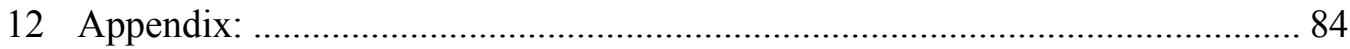

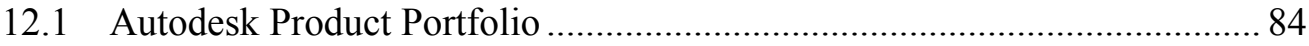

12.2 Moldflow Advisor Summary Report of fill Analysis............................... 87 


\begin{abstract}
Traditional design decisions have been based on a product's performance, quality, and price. There is an assumption that the development of products with environmental-conscious characteristics is more cost intensive than traditional design. Critical decisions to the cost for recycling and disposal are done in the early phases of product development and significantly affect environmental performance for the entire product life-cycle.
\end{abstract}

It is difficult to persuade manufacturers to make changes to the product that would improve the environmental impact, especially when changes occur in additional cost or have a negative effect on the performance, functionality or affordability. Therefore it is even more important to have an effective and efficient design development process and the ability address environmental issues as part of it.

The purpose of this thesis is to describe various tools and methods, for usage during the design development process, to optimize the use of material, reduce waste and make products more sustainable.

Autodesk is represented as supplier for 3D CAD, simulation and analysis software solutions and those will guide us in improving workflows during the product development process.

Starting with the challenges in the product development process, the thesis focuses on the design of plastic products and how mold fill simulation and other tools can impact the environmental quality. The topic of optimization for material reduction by using FEA analysis and simulation of energy loss is also discussed. 


\section{Introduction}

Environmental concerns are becoming increasingly important to producers and customers alike. With that, product disposal, along with the treatment of waste from production requires attention during the design of both, the product and the process (Blanchard and Fabrycky, 2006).

For a design development project it is vital to look at the entire product life-cycle and understand where the key environmental impacts are. A general challenge manufacturers are facing, is that innovative product design often involves new materials and processes - and that can be hard to acquire (Ashby and Johnson, 2009). In order to perform tests on objective things like performance, safety and energy, manufacturers rely on physical prototypes, which can result in high development costs. Design technology can play a key role to remove obstacles and help designing products which are more efficient, use less materials or energy.

The purpose of this thesis is to describe methods and tools in the product design development that have an impact on achieving environmental design targets. Autodesk has been chosen as a software vendor due to their comprehensive product portfolio and market position in the CAD and simulation market.

The first part of the thesis will describe fundamentals of the factors for promoting environmental design practices. ECO Labels and regulatory directives are considered as an important driver for environmental design and they are listed as important mechanisms to communicate the environmental performance of a product (Wimmer, et al., 2004). A comparison of the various types of ECO labelling is provided by Lee and Uehara, (2003). In addition, the most popular directives and regulation are illuminated in this section.

By developing a new product, or updating an existing product, there are many factors influencing the design process for improvements on the environmental impact. 
While many manufactures are concerned about implication from cost standpoint, internal and external influences are defined by Ashby and Johnson (2009) and considered as driving parameters for product design.

Furthermore the development process from a product-life-cycle perspective will be illustrated, including typical considerations for recycle and disposal of the product at the end-of-life. This section concludes with a summary of the framework for principles of environmental engineering based on the IEEE paper "Design through the 12 Principles of Green Engineering” (Anastas and Zimmermann, 2007)

Throughout the development process there are numerous challenges that prevent the cost-effective development of environmental conscious products, such as the communication of engineering changes and the creation of a physical prototype for performance testing. We will look into the process of digital prototyping and how simulation can help to address some these issues.

During the work various simulation methods and technologies are introduced. It is not the intention to describe those technologies in detail rather than bringing them into perspective of improving the design process from an environmental point of view.

Parts of the thesis have been presented at the IFAC International Workshop on “Supplemental Ways for Improving International Stability” SWIIS 2010 in Prishtina. (Kaltseis, 2010)

The thesis concludes with a summary of potential business benefits and some recommendations for further works on this topic. 


\section{Fundamentals}

According to the ASME/Autodesk 2010 study on sustainability design, there is an increase of $6 \%$ over the last year on engineers who believe sustainable design will be further incorporated into their work. With 3000 responses to the survey, more than $24 \%$ reported that their companies were extremely involved and $43 \%$ somewhat involved in sustainability design efforts. (Winters, 2010)

More than $70 \%$ also responded that their companies produce designs to specifically comply with governmental standards and regulation. Standards and regulations are considered as an important driving factor for environment friendly product design. Based on the book System Engineering and Analysis, Blanchard and Fabrycky (2006), we will indicate additional promoting factors for environmental design practices. An Overview of available ECO-labels based on ISO 14020 and regulatory directives is provided based on the book Ecodesign Implementation, Wimmer, et al., (2004) and EU directives (European Union, 2010abcd).

\subsection{Factors for promoting environmental design practices}

The reuse value of recoverable materials and components from most products at the time of disposal is usually small in relation to the production cost. Accordingly, it is difficult to persuade manufacturers to make changes to the product that would improve the eventual case of recovery of these materials.

This is especially true if those changes create costs or have even a small effect on performance, functionality, or affordability (Blanchard and Fabrycky, 2006).

However this situation is changing. Most leading companies have increasingly taken initiatives to optimize unsustainable products, processes, and systems that are currently in place. Also, market opportunities are expanding for the production of environmental friendly products. 
The following factors are recognized by Blanchard and Fabrycky (2006), System Engineering and Analysis, as primary drivers toward environmental cautiousness:

\subsubsection{Competitive differentiation}

Traditional design decisions have been based on a product's performance, quality, and price. In the world-class competition of today, some non-price factors are been included in the company's competitive strategy. All signs indicate that environmental impacts, one of the non-price factors, became the most important issue in the commercial world. ECO-labeling is an important method to communicate the environmental performance of a product as competitive advantage (Wimmer, et al., 2004). ECO-labels are explained in chapter 2.2 in further detail.

\subsubsection{Customer consciousness}

Most people believe that a healthy natural environment not only enhances their quality of life, but assures them that the quality of life will be sustained.

Customers are becoming increasingly concerned about the environmental quality of the products they use and the quality of the environment in which they live. Consumer awareness of potential damage inflicted on the environment by abuse of technology is beginning to create pressure to develop green products and clean manufacturing operations. Regulatory bodies tend to respond to this change in attitudes by developing legislation for use against those that neglect environmental issues.

Based on the Green Shopper study done by GMA/Deloitte, 2009 with more than 6,000 shoppers at 11 leading U.S. retailers, in total, approximately 54\% consider sustainability as a decision-making factor in product and store selection, and one of five consider it a dominant factor in many product categories. (Figure 1) 


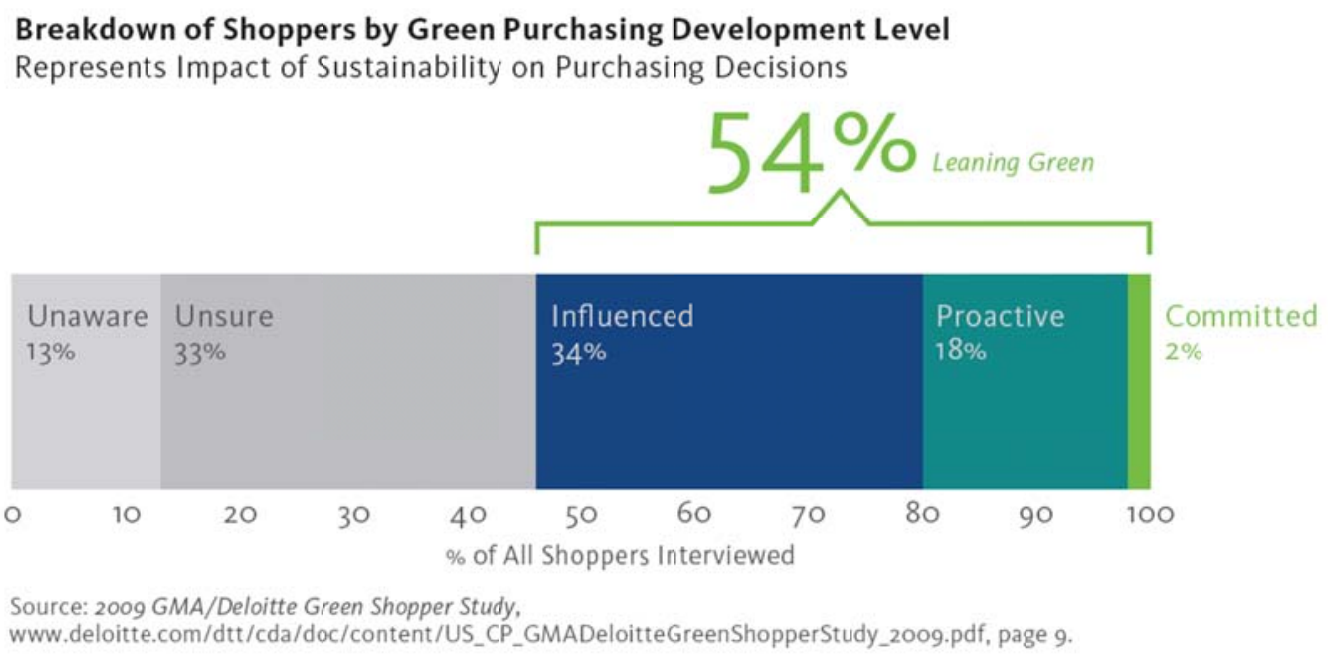

Fig. 1 Impact of purchasing decisions - GMA/Deloitte (2009) Green Shopper Study

\subsubsection{Governmental regulatory pressures}

Pending environmental legislation is expected to impose environmentally related restrictions on industrial and consumer product manufacturers. To address environmental problems, regulations inspired by causative principle are emerging. Motivated by environmental laws and customer's environmental consciousness, manufacturers are forced to consider seriously how to produce greener products and to maintain competition at the same time.

\subsubsection{Profitability improvements}

An eco-design approach to systems can have a significant impact on profitability through savings in manufacturing and other operating costs, by waste eliminationrelated strategies, and through increased market share. A growing trend toward safer product design and production satisfies a company's responsibility to provide a safer, healthy working environment for its employees. Incorporation of such values into business activities contributes to a positive feeling about their workplaces.

\subsubsection{International standards}

Coordinated by the International Standards Organization (ISO), many manufacturers are participating in a worldwide effort to establish standards for environmental stewardship over the full product life cycle. 


\subsection{ECO Labels as a driver for environmental design practices}

Wimmer, et al., (2004) describes the communication of environmental performance for the improved product equally important than the design process itself.

Environment labeling, although it is voluntary in nature, can exert significant impact on the market if the environmental awareness of consumers is high. By highlighting the difference or improvements over the other products, one can distinguish the product from others. Many companies use ECO labels to increase market share of the product and to enhance their corporate image. Products that cannot obtain the label, or choose not to apply, may have a competitive disadvantage to products that do have the label. ECO labels according to the ISO 14020 standard are subdivided into the following categories:

- Type I ECO Labeling

- Type II Self-declared Environmental Claim

- Type III Environmental Product Declaration

\subsubsection{Type I ECO Labeling}

Type I environmental labeling according to the ISO 14024 standard is a voluntary system that is widely used in many parts of the world and requires certification by an independent third party organization. To meet the requirements of the Type I environment labeling program awards, a set of predetermined requirements based on lifecycle considerations need to be met.

Products that meet the specific values imposed by the program can obtain the label and are certified to carry a logo on the product. Usually only 20 to $30 \%$ of the products within a category are awarded labels due to a selective principle. (Wimmer, et al., 2004) 
Examples of well-known ECO labels are listed in Table 1:

Table 1 Eco-lables, (Wimmer,et al.,2004)

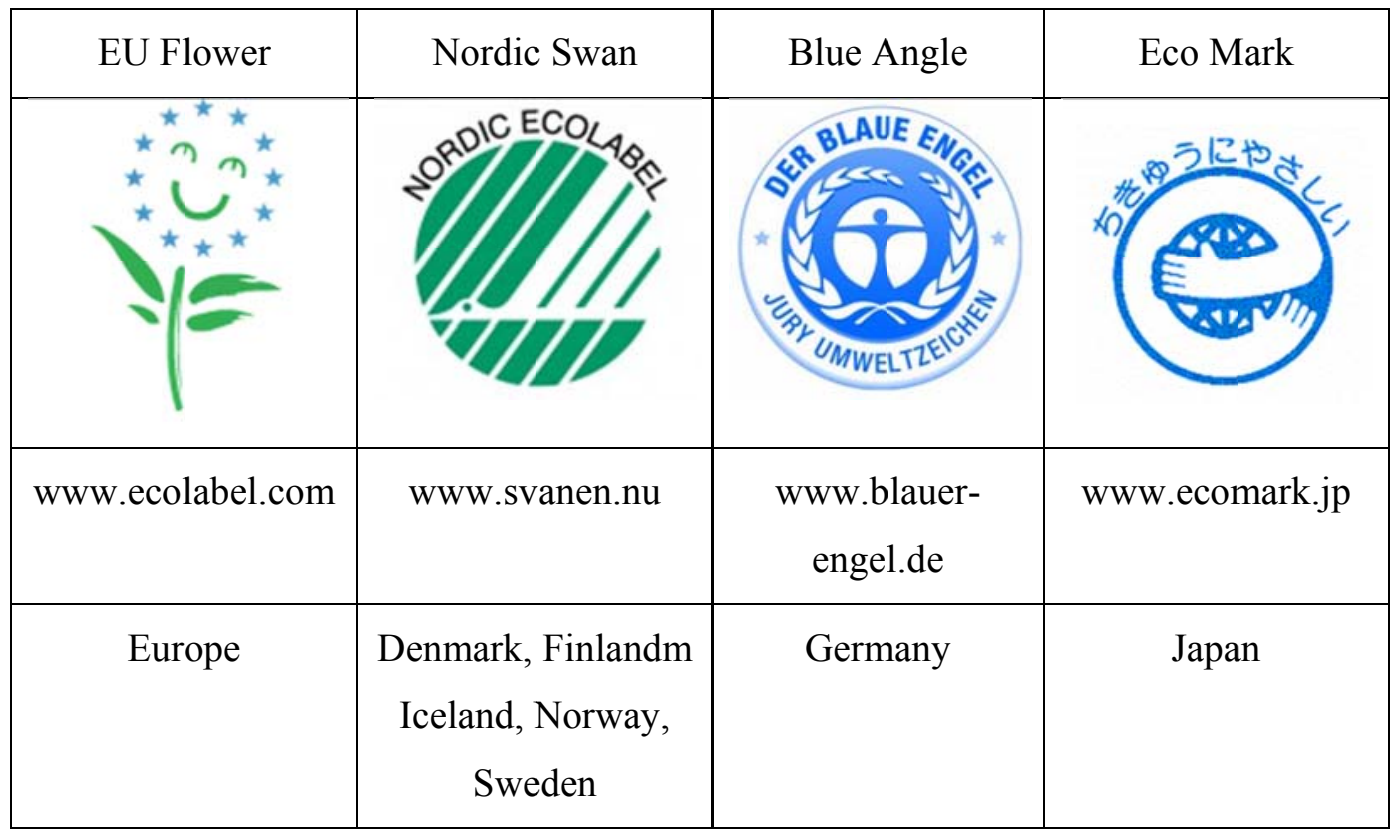

\subsubsection{Type II Self-declared Environmental Claim}

According to ISO 14021, self-declared environmental claims can be made without independent third-party certification. Environmental aspects of a product are indicated by statements, symbols or graphics. There are twelve selected terms that represent commonly used environmental claim statements: Recyclability; Recycled Content; Reduced Resource Use; Recovered Energy; Waste Reduction; Reduced Energy Consumption; Reduced Water Consumption; Extended Life Product; Reusable and Refillable; Designed for Disassembly; Compostable; and Degradable.

The environmental claims are often very difficult to verify and can lead to confusion by the consumer. They are often counter-productive in helping the consumer to make an informed decision. To avoid the confusion, regulations in the use of environmental claims are introduced and many are mainly based on the ISO 14021 standard. 


\subsubsection{Type III Environmental Product Declaration (EPD)}

Unlike ECO labeling, only a logo or self-declared claims, the EPD presents environmental aspects throughout its entire Life-cycle and other product related environmental information. Quantified information of the products environmental loads and impact are extracted from the LCA results and presented in a categorized manner.

The typical target audience for an EPD can be usually found in the B2B environment (e.g. supply chain manufactures), or B2C (e.g. retail and institutional level consumers). According to the ISO 14040 standard, LCA data are critically reviewed

by an external, independent third party organization and define the basics for the EPD. (Wimmer, et al., 2004) 


\subsection{Different types of environmental labels in comparison}

As shown in Table 2), environmental labels are targeted at different market segments. Lee and Uehara (2003); Wimmer, et al., (2004) describe the different types of environmental labels and declarations, the advantages, disadvantages and the use in various application areas.

Table. 2 Types of environmental labels - Lee and Uehara (2003)

\begin{tabular}{|c|c|c|c|}
\hline Item & Type I & Type II & Type II \\
\hline Generic Name & ECO Labeling & $\begin{array}{l}\text { Self-declared } \\
\text { Environmental Claim }\end{array}$ & $\begin{array}{l}\text { Environmental Product } \\
\text { Declaration }\end{array}$ \\
\hline Target Audience & Retail Consumers & $\begin{array}{l}\text { Retail/Industrial/ } \\
\text { Institutional } \\
\text { Consumers }\end{array}$ & $\begin{array}{l}\text { Industrial/ } \\
\text { Institutional/Retail } \\
\text { Consumers }\end{array}$ \\
\hline $\begin{array}{l}\text { Communication } \\
\text { Method }\end{array}$ & Environmental Label & Text and Symbol & $\begin{array}{l}\text { Environmental Profile } \\
\text { Data sheet }\end{array}$ \\
\hline Scope & Whole Life Cycle & Single aspect & Whole Life Cycle \\
\hline Use of LCA & No & No & Yes \\
\hline Advantage & $\begin{array}{l}\text { Easily identified } \\
\text { Quick decision } \\
\text { Credibility through } \\
\text { third party }\end{array}$ & $\begin{array}{l}\text { Market oriented } \\
\text { Flexible approach to } \\
\text { market needs } \\
\text { Tool for inter-business } \\
\text { competition }\end{array}$ & $\begin{array}{l}\text { Detailed data via } \\
\text { common method } \\
\text { Credibility via } \\
\text { scientific quantitative } \\
\text { data }\end{array}$ \\
\hline Disadvantage & $\begin{array}{l}\text { Uses only a symbol } \\
\text { (logo) } \\
\text { No detailed } \\
\text { information } \\
\text { No linkage to } \\
\text { company's unique } \\
\text { effort }\end{array}$ & $\begin{array}{l}\text { Relatively low } \\
\text { credibility } \\
\text { Need to face consumer } \\
\text { directly (no third party) } \\
\text { Claim is about single } \\
\text { issue or limited }\end{array}$ & $\begin{array}{l}\text { Complicated LCA } \\
\text { analysis } \\
\text { Insufficient back- } \\
\text { ground data } \\
\text { Not easy to implement }\end{array}$ \\
\hline Application Area & $\begin{array}{l}\text { Home use products } \\
\text { Simple function } \\
\text { products } \\
\text { Low priced products }\end{array}$ & Products in general & $\begin{array}{l}\text { Products for industrial } \\
\text { use / relatively } \\
\text { complicated and high } \\
\text { priced products / } \\
\text { durable products }\end{array}$ \\
\hline Standard & ISO 14024 & ISO 14021 & ISO 14025 \\
\hline
\end{tabular}




\subsection{Regulatory directives}

There are several directives and laws available worldwide concerning environmental regulations. With the directives of WEEE, RoHS, EuP and REACH the European Union provides a legal framework for environmental standards. Some of the most popular directives are listed in section 2.4.1 to 2.4.4.

\subsubsection{WEEE (Waste from Electrical and Electronic Equipment)}

The growing amount of waste from electrical and electronic equipment as well as the content of hazardous components has become a major concern within the EU. The WEEE directive aims to prevent, reduce, reuse, recycle and recover waste of electrical and electronic equipment. It requires the collection of waste electrical and electronic equipment and the recovery and re-use or recycling of waste collected (European Union, 2010a).

The end users opportunities and behavior has to be considered for the disposal of a product according to WEEE. A logo is printed on each product advising not to be dispose, but bring it back for recycling (see Figure 2)

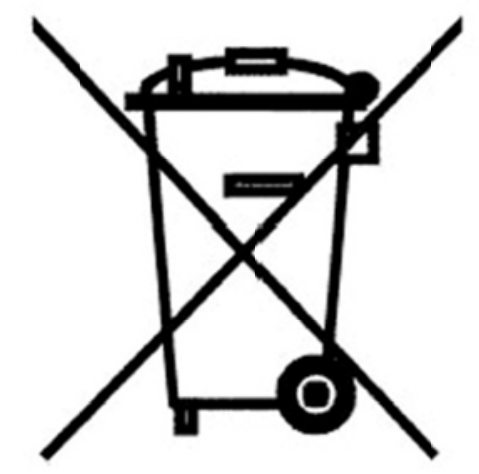

Fig. 2 WEEE symbol for marking products

The directive is based on producer responsibility and the polluter pays principle. The producers of equipment are responsible for providing financing for the collection, treatment, recovery and environmentally-sound disposal of WEEE deposited at collection facilities (European Union, 2010a). 


\subsubsection{RoHS (Reduction of Hazardous Substances)}

Innovation cycles for many electrical and electronic products are short, and such products often contain a great variety of materials and components, some of which are hazardous. Anastas and Zimmermann, (2007) mentions as a first step towards an environmental friendly product the elimination of hazardous materials.

The RoHS Directive is intended to restrict the use of certain hazardous substances in electrical and electronic equipment. This increases the protection of human health and aids the environmentally-sound recovery and disposal of waste electrical and electronic equipment.

The ban of four heavy metals (lead, cadmium, mercury, hexavalent chromium) and two categories of brominated flame retardants (PBBs and PBDEs) entered into force in July 2006, although certain applications of these substances have been temporarily exempted until their substitution becomes scientifically and technically feasible (European Union, 2010b).

\subsubsection{EuP (Energy using Products)}

The Ecodesign directive provides with consistent EU-wide rules for improving the environmental performance of energy related products through ecodesign.

The production, distribution, use and end-of-life management of energy-using products (EuPs) is associated with a considerable number of important impacts on the environment, namely the consequences of energy consumption, consumption of other materials/resources, waste generation and release of hazardous substances to the environment. 
It is estimated that over $80 \%$ of all product-related environmental impacts are determined during the design phase of a product. Against this background, Ecodesign aims to improve the environmental performance of products throughout the life-cycle by systematic integration of environmental aspects at a very early stage in the product design. (European Union, 2010c)

The proposal does not introduce directly binding requirements for specific products, but does define conditions and criteria for setting, through subsequent implementing measures (European Union, 2010c).

\subsubsection{REACH (Registration, Evaluation and Authorization of Chemicals)}

With providing appropriate safety information to their users, REACH makes the industry responsible for assessing and managing the risks posed by chemicals. Since coming into effect in 2007, manufacturers or importers of chemicals must register chemicals (European Union, 2010d).

All manufacturers and importers of chemicals must identify and manage risks linked to the substances they manufacture and market. For substances manufactured or imported in quantities of 1 ton or more per year per company, manufacturers and importers need to demonstrate that they have appropriately done so by means of a registration dossier, which must be submitted to the European Chemicals Agency (ECHA) (European Union, 2010d). 


\section{State of the art}

Based on the books "Cost-Efficient Design" (Ehrlenspiel, et al., 2006) and "Materials and Design" (Ashby and Johnson, 2009) we will describe the product design processes from cost perspective and other influential factors in product design.

Supplementary insights to the life-cycle of a product, the life-cycle analysis, and the relationship to recycling and disposal are described based on the book "Ecodesign Implementation" (Wimmer, et al., 2004) and "Systems Engineering and Analysis" (Blanchard and Fabrycky, 2006).

In addition the IEEE paper "Design through the 12 Principles of Green Engineering" (Anastas and Zimmermann, 2007), provides a framework for achieving sustainability through science and technology.

\subsection{Product design from a cost perspective}

There is a general assumption that environmental consideration in manufacturing drive additional costs to the product overall production costs. This can certainly be true, if environmental considerations are added late in the design development process. However, if the environmental considerations are done in the very beginning, it can have a positive effect to the overall cost. There is a direct relationship between environmental impact and costs. The design of products which are more efficient, use less materials or energy can bring benefits to both, producers and consumers. (Willis, 2009)

The product development phase leads the start of regular production. On average, approximately $88 \%$ of the total product costs are committed by the technical planning department (product development and product planning). (Fig3.) In contrast, all decisions made afterwards determine only $12 \%$ for the remaining production-cycle of the product (Ehrlenspiel, et al., 2006). 
Likewise, the environmental performance is defined in the early phase of product development. Critical decisions to the cost for recycling and disposal are significantly affected by product design decisions.

\section{Production costs in \%}

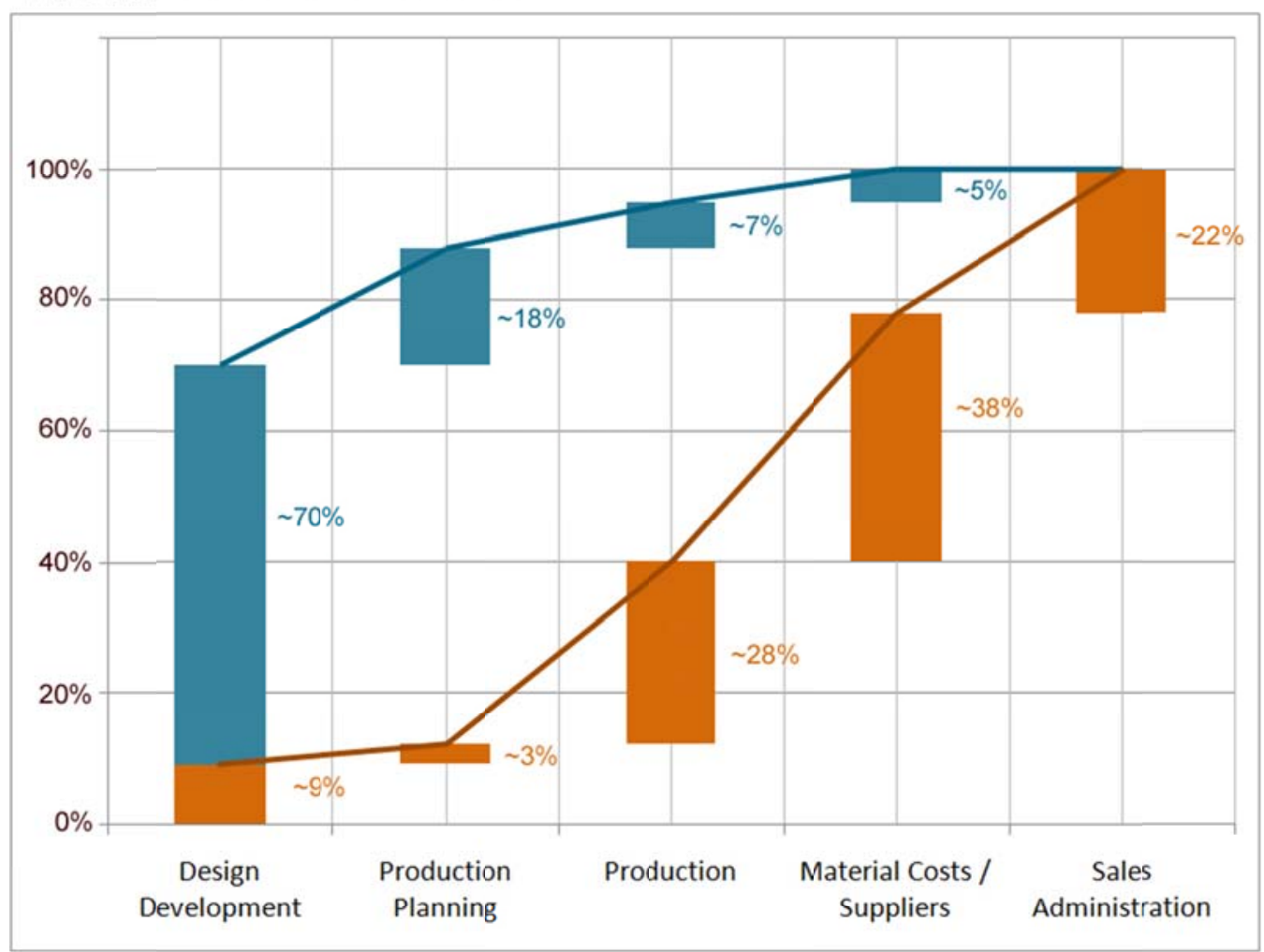

Costs set (established)

Fig.3 Production costs in \% - according to Ehrlenspiel, et al., (2006)

A company's largest costs arise in production with $28 \%$ and purchasing with $38 \%$ on average of the product costs. Many companies give this the greatest attention to rationalize and reduce costs. However, in the line with a growing focus on environmental issues, manufactures are optimising the use of product materials to reduce waste and make products more sustainable. They are increasingly realizing, however, that to achieve this, they need to reduce operating inefficiencies. Design technology can play a key role here also in allowing manufactures to drive faster time to market and reduce time spent on process issues. 


\subsection{What influences product design?}

The design process is subject to be influenced by a number of external and internal factors. The definition of a product can be simplified through the analysis of possible impacts and determination of influences. Figure 4 shows the driving elements in the design development process defined by Ashby and Johnson (2009).

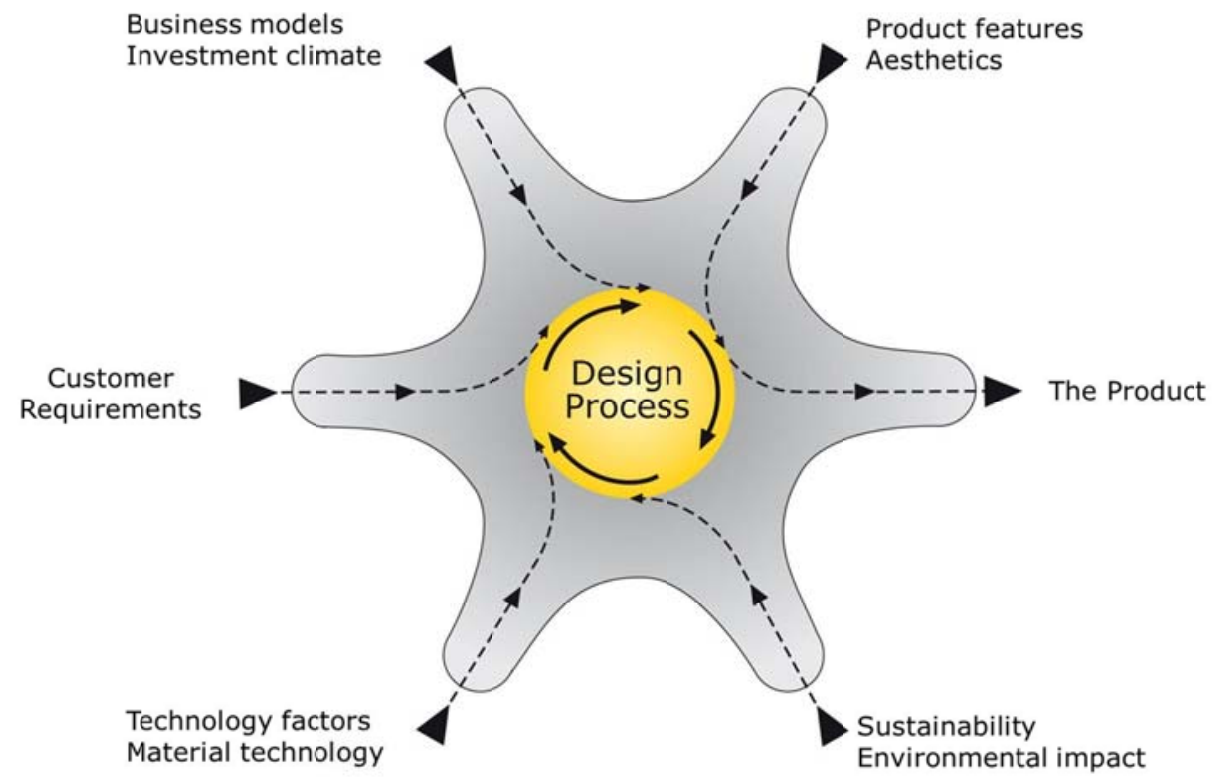

Fig. 4 Inputs to the design process - according to Ashby and Johnson (2009)

Over the entire product life-cycle there is a lot of interaction between the product and its environment. Different relations might influence the products performance and the effects on the environment. Wimmer, et al., (2004) suggest the adoption of the principles in considering time-related changes and the thinking in alternatives by working from an overall to a detailed view in the design development process.

Considering time related changes requires the anticipation for future events and their integration into the modeling process. Previously developed models should be evaluated against new, relevant knowledge. 
This includes typical trends such as more restrictive environmental laws and standards, changing consumer behavior due to changing life-style or higher demand due to changes in the demographic distribution of people in industrial countries. Some of those are related to environmental issues.

Wimmer, et al., (2004) also mentions, by working from an overall view to a detailed view ensures to keep the focus on relevant aspects of the product system, the development of an optimal solution through a stepwise procedure and the limitation of planning expenses.

Ashby and Johnson, (2009) define the elements of the integrated design process as follows:

\section{Customer Requirements}

The design process generally commences with the identification of a "want" or "desire" for something and is based on a real (or perceived) deficiency. In the developed countries many products have saturated, almost everyone who needs them, has them. The market force is generated by desire ("want") not necessity ("need").

Numerous product designs today are driven by desire, and one of the things consumer desire is greater functionality. It is usual to suggest that designers respond to market needs, but sometimes it is the designer who creates the need. It is important that the results reflect a true customer requirement, particularly in today's environment where available resources are limited.

\section{Technology factors}

New technologies that enable innovation in material and processes influence and stimulate the product design process. The drive towards miniaturization creates new mechanical and thermal requirements and drives the discovery and development. Science reveals new technologies, from these technologies new materials and processes emerge. These in turn, stimulate new opportunity for product design. 


\section{Sustainability and the Environmental impact}

Considering the entire life-cycle of a product, the sum of undesired byproducts exceeds the capacity of the environment to absorb them. Material reductions are made possible by recycling, by use of renewable material made from things that grow, by miniaturization and by replacing goods and services.

Energy reductions can be achieved by lightweight design of transport systems, by optimized thermal management and by increased efficiency of energy conversion and utilization in industry.

Blanchard and Fabrycky, (2006) mention, an evolutionary design paradigm, that starts with considerations of environmental impact caused by the products and product related processes is known as environmental conscious design and manufacturing. A significant difference to waste management and pollution prevention is seen in the proactive approach. The objective is to reduce environmental impact in the early stages of the design.

\section{Economics and Investment Climate}

Many product designs have never reached the marketplace. Translating a design into a successful product requires investment, and investment depends on confidence, on establishing economic viability. In the rapidly changing technology world of today, the speed at which new products can be brought to the market often determines the financial success of a company. The investment required to commercialize a technically viable product will be forthcoming only of if the technical, market and business case assessment are all attractive.

\section{Product features and Aesthetics}

Aesthetics arouse interest, stimulate and appeal. Form follows function. Both, technical and industrial design influences the product success. 


\subsection{The life-cycle of a product}

Environmental conscious product design requires a look at all the environmental influences in the total life-cycle of the product. The environmental impact in the different stages are generated from inputs e.g. energy and material resources and outputs e.g emissions to earth, air and water. Also, each stage may have an effect on the production of waste and potential problems with health and safety. (Wimmer et al., 2004; Gordon, 2001)

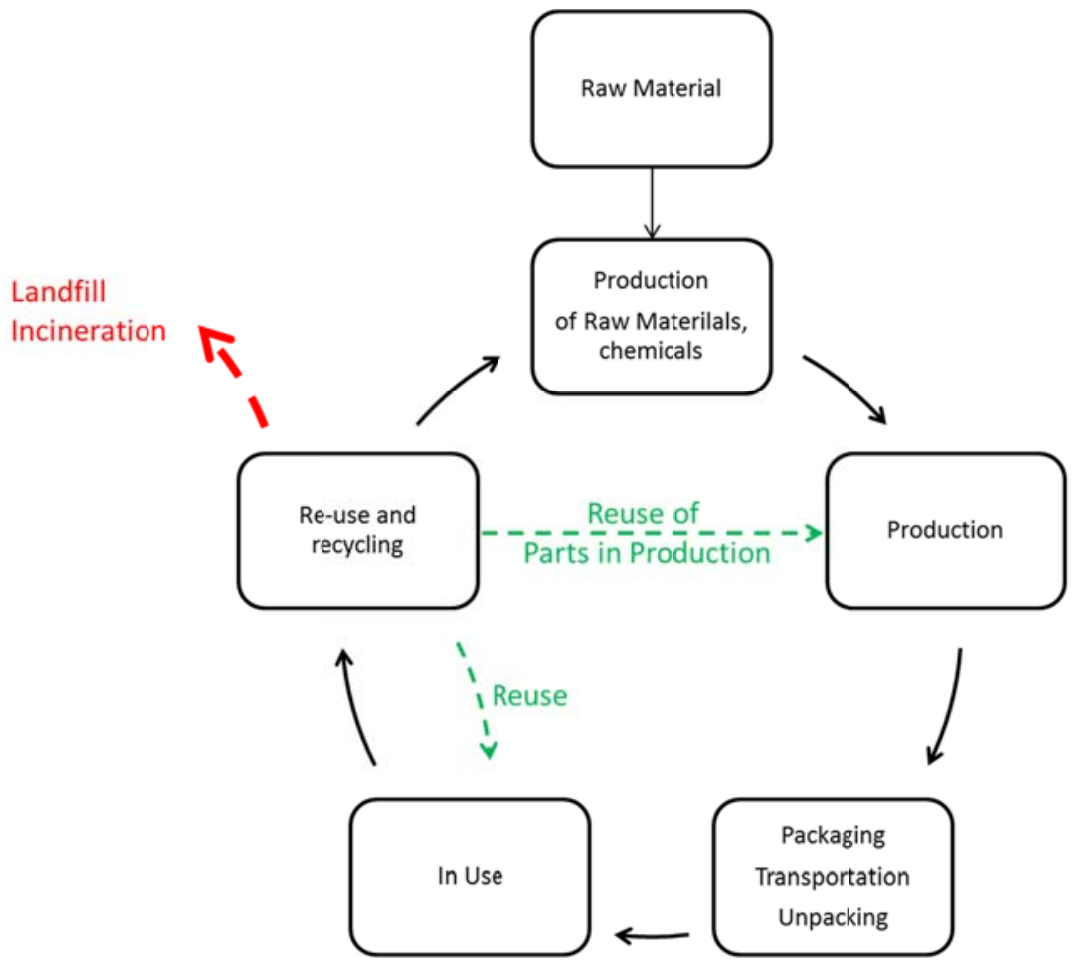

Fig. 5 The Lifecycle of a product - according to Blanchard and Fabrycky, (2006)

There is no net sustainability advantage, if a product is energy efficient but the manufacturing process consumes energy to a degree that offsets any energy gain. (Anastas and Zimmermann, 2007) 


\subsection{Life-cycle analysis}

A life-cycle analysis (also known as cradle to grave analysis) is the holistic investigation and valuation of a product over its entire life, from the first stage of material acquisition to the final stage of disposal and waste management. Designers should consider the entire life cycle of a product including materials and energy inputs.

A framework for LCA has been standardized by ISO 14040 series. It consists of four phases (Wimmer, et al., 2004):

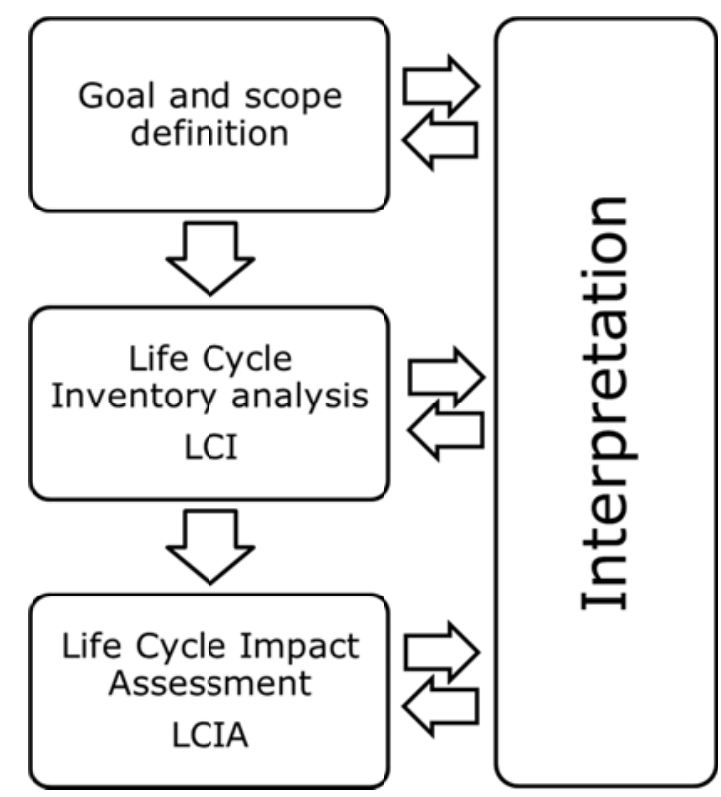

Fig. 6 The four phases of LCA (Wimmer, et al., 2004)

\section{Goal and scope definition}

With the definition of the goal and intended use of the LCA, the scope concerning system boundaries, function and flow, required data quality, technology and assessment parameters is assessed.

\section{Life Cycle Inventory analysis, LCI}

The LCI is an activity for collecting data on inputs (resources and intermediate products) and outputs (emissions, wastes) for all the processes in the product system. 


\section{Life Cycle Impact Assessment, LCIA}

In the phase of the LCA inventory data on inputs and outputs are translated into indicators about the product systems potential impacts on the environment, on human health, and on the availability of natural resources.

\section{Interpretation}

With the interpretation, the results of the LCI and LCIA are interpreted according to

the goal of the study and where sensitivity and uncertainty analysis are performed to qualify the results and the conclusions. 


\subsection{Life-Cycle Relationships for Recycling and Disposal}

During the life-cycle of a product there are different stages of the evaluation for reuse, recycling and disposal. Blanchard and Fabrycky (2006) describe in Figure 7 the relationship of recycling and disposal within the various stages of a product lifecycle. Components and material are subjected to a classification and decision procedure that will focus on the design characteristics supporting disposability. If environmental requirements are well specified during the design phase, the classification can help in the implementation of environmental friendly recycle and disposal procedures.

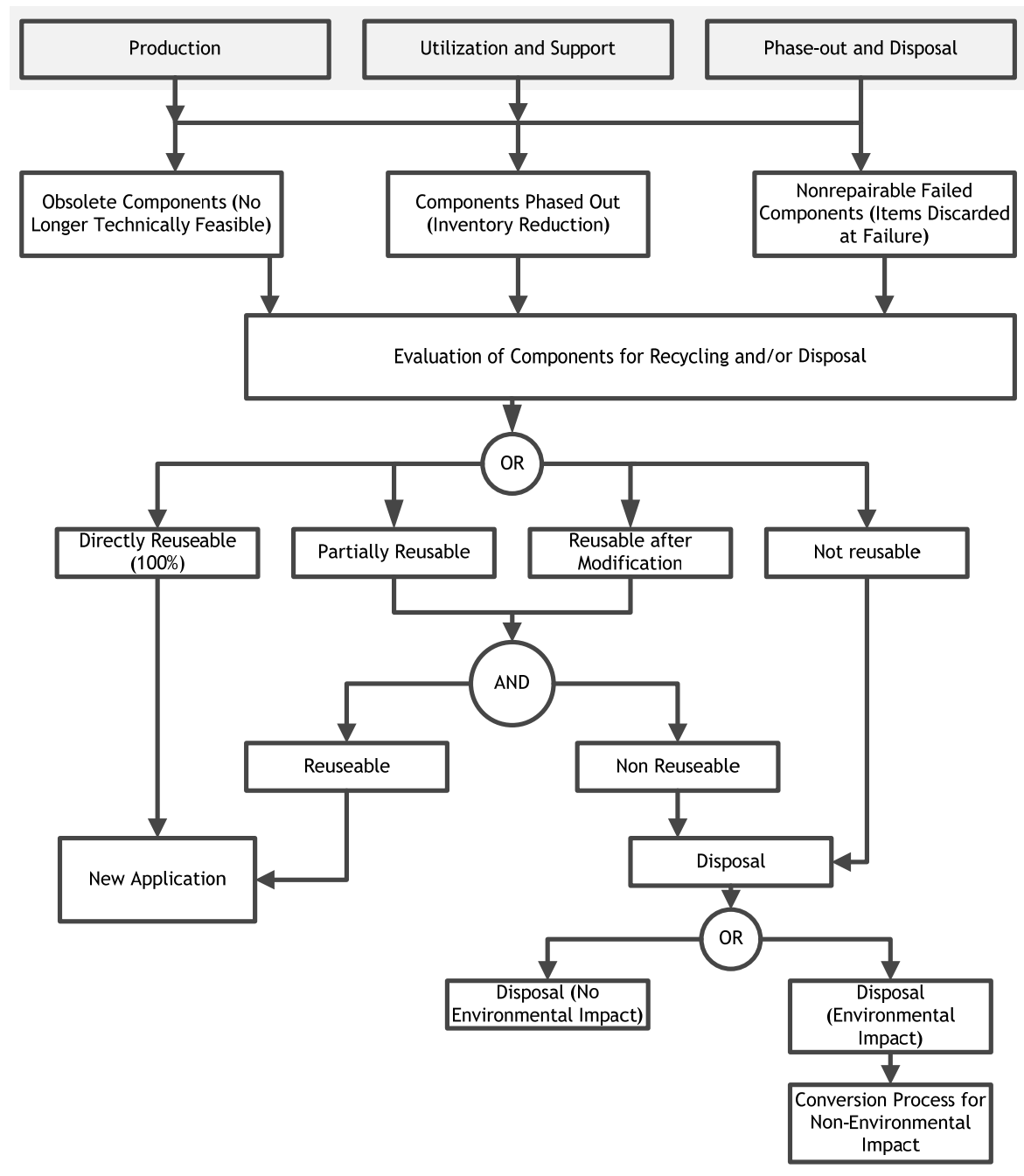

Fig. 7 Component/Material retirement, phase out, recycling and disposal relationship (Blanchard and Fabrycky, 2006) 
By considering recyclability and disposability as a design dependent parameter, producers are able to predict and compare alternatives. If environmental requirements are specified well, design alternatives can be evaluated against them along with other requirements.

Blanchard and Fabrycky, (2006) describe the essential processes for the purpose of reuse, remanufacture/redesign and recovery/recycling. Both, the manufacturing and de-manufacturing processes are affected by design decisions.

\section{Reuse}

Energy and material resources are saved be designing them for reuse. Reuse is the highest form of waste reduction and potentially increases the end-of-life value. Reuse is most easily justified in the case of components with high manufacturing costs, long innovation cycles and long lifetime.

\section{Remanufacturing/Redesign}

Remanufacturing is the redesign of a product and its life cycle to minimize environmental impact and increase value. Another strategy is inverse manufacturing, where the useful life of the product is prolonged by designing reuse features into it. Remanufacturing requires disassembly efforts that contribute to the demanufacturing cost. The recycled components and parts may be used for reproduction either the same or for different products, according to the closed loop or open-loop recycling concept.

\section{Recovery/Recycling}

With recycling, waste is recovered and transformed into new products and materials. In addition, when waste is recycled, the energy needed to extract new natural resources is saved. The reduction of disposal volume and costs, recovery from products to obtain raw materials or reusable components is most important. 


\subsection{Defining the different types of environmental waste in manufacturing}

With the rapid growth in population and widespread manufacturing, the generation

of wastes associated with the production, use and disposal of goods and services is of great concern. These byproducts of market transaction impact the environmental quality (Blanchard and Fabrycky, 2006).

Under the principles of lean production, non-value added activities are considered as waste and need to be eliminated. There is a close connection between the lean thinking and environmental efficiency. Lean thinking promotes waste reduction at every stage of a life-cycle of a product. Willis, (2009) derives the basics of lean production into seven types of waste from an environmental perspective.

- Energy

- Water

- Material

- Garbage

- Transportation

- Emission

- Biodiversity

\section{Energy}

Energy is often used to describe a broad range of activities, but in context of environmental waste it refers to the consumption of electricity and fuels to power devices.

Figure 8 displays how the energy consumption differs throughout the life-cycle by the type of the product. On average, the energy consumption for the production of an 
automobile (materials and manufacturing) takes account for only $16 \%$ compared to $84 \%$ for transport, usage and disposal (Ashby and Johnson, 2009).

To reduce energy waste, the entire life-cycle of a product needs to be taken into account, rather than a single area of the product.

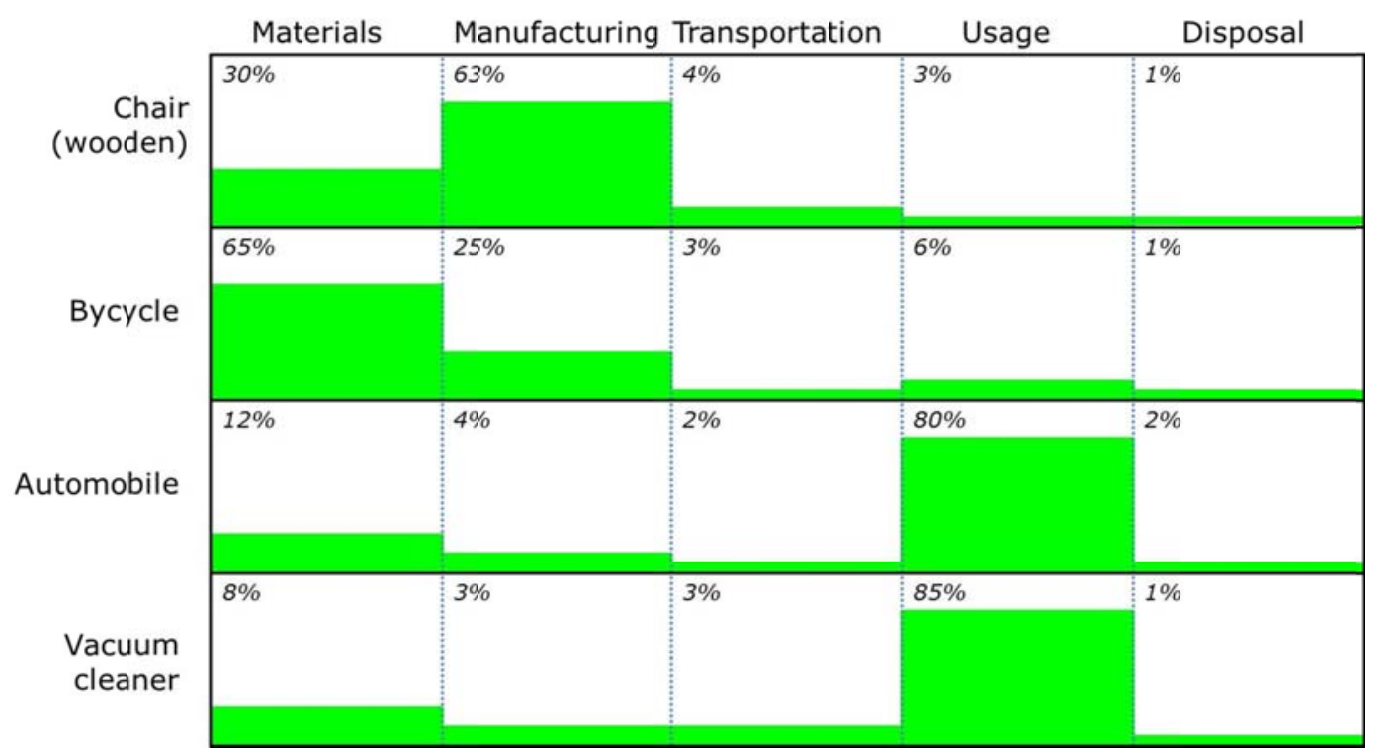

Fig.8 Energy consumption during product life-cycle, Ashby M. and Johnson K. (2009)

Material selection and reduction has great impact on the energy consumption. Cheah, et al., (2007) describes that lighter vehicles - cars, trains, planes, and automobiles use less energy. Every 10\% weight reduction in a car decreases fuel consumption by 6 to $7 \%$.

\section{Material}

Material exerts a profound influence on the environmental impact of a product. The most obvious way to conserve material is to make products smaller, make them last longer and recycle them when they reach end of life. By eliminating or reducing material waste, the need of virgin material to make a product is reduced. 


\subsection{Principles of Environmental Friendly design}

Based on the IEEE paper "Design through the 12 Principles of Green Engineering" (Anastas and Zimmermann, 2007), the fundamentals for achieving sustainability through science and technology are described. Those principles will guide us for applying tools and methodologies in the product development cycle and provide a systematic and comprehensive framework for green engineering that moves beyond baseline engineering quality and safety specifications to consider environmental, economic, and social factors.

\section{Hazardous material}

It is not an economically or environmental sustainable approach to put effort into minimizing hazardous substances. The inherent nature of selected material and energy inputs should be evaluated as a first step toward a sustainable product. For hazards that are eliminated in process through purification or cleanup steps from the final product, there is still a risk of failure for safety precautions, storage and disposal. All material and energy inputs and outputs are required to be inherently non-hazardous as possible to reduce the risk of failure and expenditure for monitoring and contact.

\section{Prevention}

It may seem to be obvious that waste generation should be avoided wherever possible. Technology targeted waste free designs are based on the concept of designing inputs to be part of outputs.

\section{Design for separation}

The ease of product separation can be impacted at the earliest stage in product design (Economic and technical limitations). Obstacles in recovery recycle and reuse is in economic and technical limitations in separating materials and components. Obstacles can be overcome by avoiding permanent bonds between two different materials. 


\section{Maximize mass, energy, speed and time efficiency}

Resources are being wasted all throughout the life cycle of a product, if a system is designed, used or applied at less than maximum efficiency.

\section{Output-pulled versus input pushed}

Output-pulled versus input pushed in manufacturing systems waste, associated with overproduction waiting time, processing, inventory can be eliminated by planning for final output, goods produced to meet the end user demand exactly for timelines, quality and quantity based on just-in-time manufacturing systems.

\section{Conserve complexity}

Recycling of material could be counterproductive and sacrifice the value for high complex, high/entropy substances (down cycling). End-of-life design decisions for recycling, reuse or beneficial disposal should be based on the invested material and energy subsequent complexity across all design scales.

\section{Durability rather immortality}

Environmental problems often results of products that last well beyond their useful commercial life. The risk to human and environmental health can be significantly reduced by targeting durability and not immortality as a design goal.

\section{Meet need, minimize excess}

Optimizing the design for the worst case scenarios or extreme an unrealistic conditions increase the material and energy costs unnecessarily. There is a tendency to design for the worst case scenarios, which requires incorporating and treating components whose function will not realized under most operating conditions.

\section{Minimize Material diversity}

When considering end-of-life decisions the diversity of materials becomes an issue and it determines the ease of disassembly. Through the use of mono-material design strategies it is no longer necessary to disassemble for recovery and recycling. 


\section{Integrate local material and energy flow}

The need to generate and acquire energy and process raw materials is minimized by taking advantage of existing energy and material flows. Anastas and Zimmermann, (2007) describe an example of a regenerative braking system in hybrid electric vehicles. Heat generated by the braking system is captured reversing the electric motor.

\section{Design for commercial afterlife}

Waste can be reduced by using a design strategy that encourages up-front modular design for components to remain functional and valuable, so they can be recovered for reuse and reconfiguration. Products that are designed that way can be used commercially after end-of-life.

\section{Renewable rather than depleting}

Virgin materials requires repetitive extractive processes; used in a consumptive manner incrementally moves the substance toward depletion. A waste product used as an alternative feedstock or recyclable input is considered renewable from sustainability perspective. 


\section{Problem description}

A product is called environmental conscious when it simultaneously satisfies the cost performance target and the environmental target throughout the entire product lifecycle. Environmental issues are so important that the manufacturing industry must consider them; however they face challenges during the product development phase.

When developing a new, or updating an existing product there many aspects to the environmental friendliness of a product. It seems to be obvious that the design phase defines the environmental consciousness for the entire life-cycle of a product. However, the reality is that companies practice little environmental considerations unless they are forced by legislation regulatory. Some of the obstacles are listed as following:

- Lack of material information

- Lack of readily available life-cycle-analyse tools

- There is no full description of the product model available

- Simulation tools are difficult to use

- Simulation tools are not readily accessible

Whether it is a new product development or responding to a specific customer requirement, the optimization begins in the initial concept design phase. While many companies rely on a physical prototype for performing test and validation of the product, this stays in contradiction with conceptual optimization. 


\subsection{Challenges in product development}

Autodesk, (2010d), mentions a number of challenges manufacturers are facing in product development. Throughout the development process of a product, manufacturing companies rely on various design tools to complete the technical description of a product.

In the initial phase of concept design, information is gathered and digital data rarely exists or is often only available in an incompatible format. The engineering team must re-create information in a format which they can use throughout the development-cycle. This results in duplication and additional conversion efforts and adds significant costs and time delay.

At a certain stage in the development, many companies rely on a physical prototype for product performance testing and validation. Based on the maturity of the product development stage, a physical prototype is built and used for testing. In the case of a required design change, manufacturing needs to go back and request modification to the original design.

The refinement of the physical prototype is an iterative process and usually requires multiple engineering change orders and is repeated in multiple cycles. (Fig. 9 Traditional design process using a physical prototype)

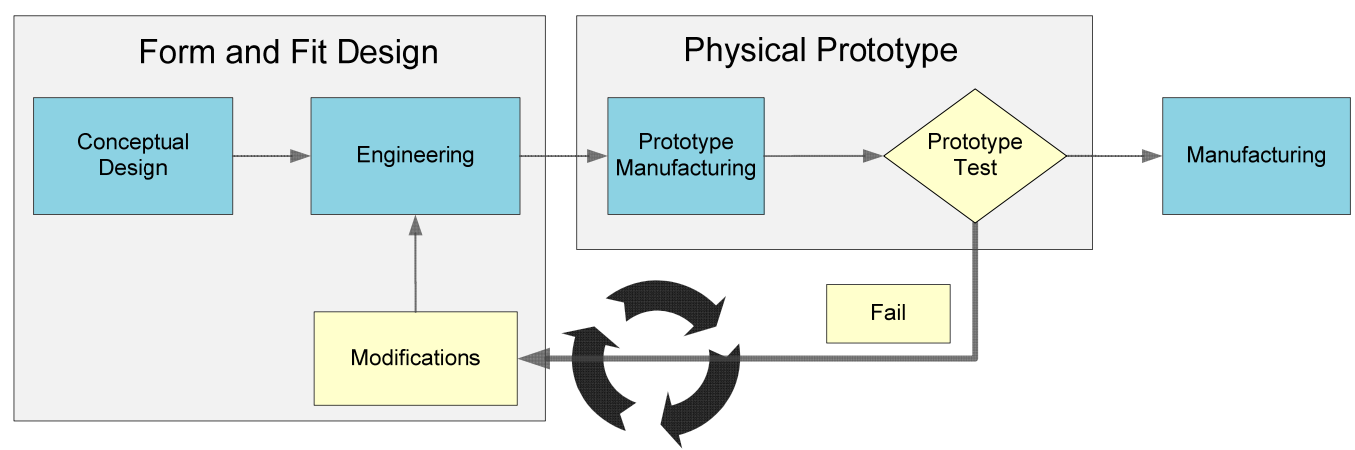

Fig. 9 Traditional design process using a physical prototype 
Also, manufacturing is heavily dependent on paper-based processes. Communication back to engineering is often done in an analogue form e.g. by doing modification on the paper drawing. Early and effective manufacturing process input is critical to make the right decisions in improving the quality of the design.

According to the 10x rule, the propagation of errors at each development stage cost 10 times the cost of the original estimates. (Ehrlenspiel, et al., 2006)

To lower the environmental impact in product design engineers need to trace new ways and innovative approaches. New technologies and materials are explored; production processes which never have been done before need to be considered, as well as new suppliers etc. This implies a high risk of failure in the development process.

Autodesk, (2010d) proposes with Digital Prototyping a method to "Get it right the first time" enabled by a simulation driven design development approach. Instead of building a physical prototype for testing, simulation and analyze is done on the virtual product.

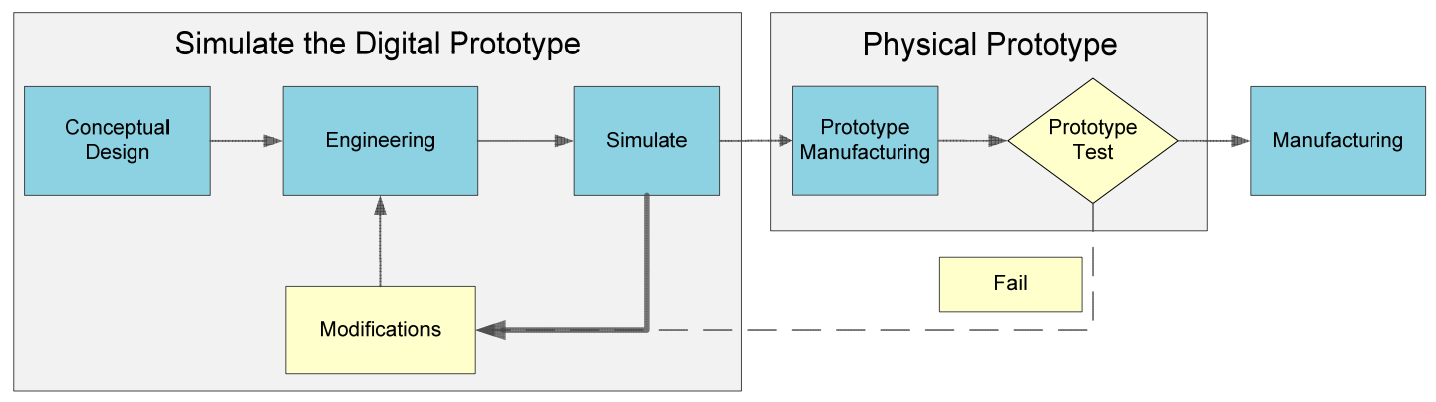

Fig.10 Design Process with simulation on a virtual model

The aim of Digital Prototyping is to reduce and eliminate the need for recreation of data and conversion efforts by maintaining a single digital prototype of the product. A digital prototype is a digital simulation of a product that can be used to test form, fit and function and enables the user to virtually explore a product before it is manufactured. 
Although there are discussions about the benefits of digital prototypes for many years, the budget or the tools required for building and testing a true digital prototype have been rarely achieved. In addition to the positive impacts on the development workflow, Autodesk's approach with digital prototyping is an enabler for environmental design considerations.

A central requirement is to keep all data digital throughout the design development lifecycle. Simulation of the digital prototype determines optimal material choice and other critical design criteria.

It is probably too idealistic to think that a digital prototype eliminates the physical prototype entirely; however a digital prototype can help to reduce the number of physical prototypes significantly.

Aberdeen Research, (2009) states that best in class companies take advantage of other methods to assess product performance that allow them to reduce physical prototypes by $37 \%$ compared to industry average. 


\section{Main Part}

Computer based simulation of $3 \mathrm{D}$ CAD models is primarily seen as a method to reduce costs and design-cycle time and increase the performance quality of products. While this has been practiced since several years, there is a potential use for improving the environmental impact while leveraging the benefits for cost and design-cycle time reduction.

When developing a new, or updating an existing product there are a lot of different ways to improve the environmental impact of a product. Many companies only focus their efforts on the operational level to reduce costs; however the design phase has a significant impact of the overall environmental performance of a product.

\subsection{The development of design knowledge - Autodesk Digital Prototyping}

Autodesk proposes digital prototyping as a design methodology that makes information available early and uses them for evaluation in a digital simulation process. By doing so, the designer is able to choose between design and material alternatives and base their decision on data rather relying on experience or tests with physical prototypes.

Figure 11 illustrates the shift of the knowledge development progress towards the earlier phases in the product development. As a consequence of that, the designer has information at the time available when costs of change are still low. Considering the dynamic of new product development this is important because unwanted design decisions which cannot be reverted later on can be avoided. 


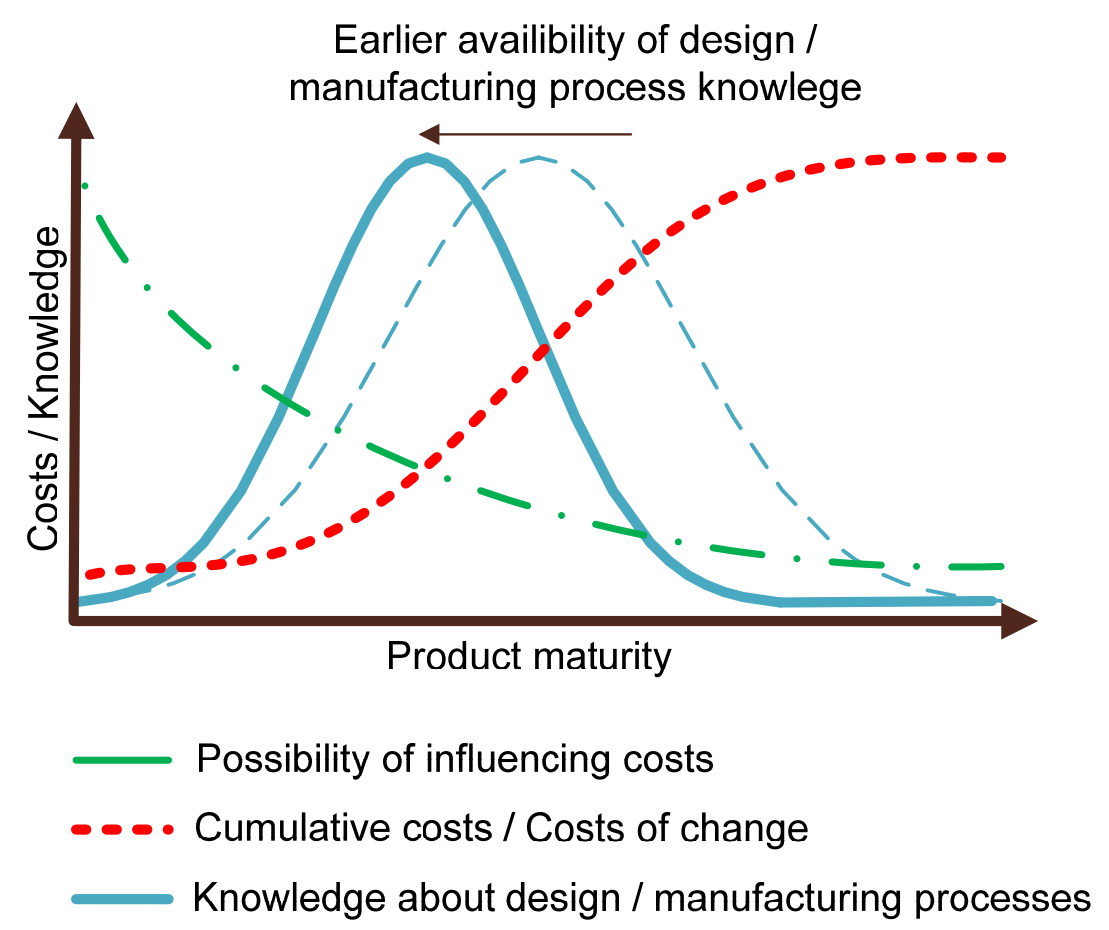

Fig. 11 Shift of knowledge development progress (Autodesk, 2010d)

The core of digital prototyping is a 3D model done by Autodesk ${ }^{\circledR}$ Inventor ${ }^{\circledR}$ describing the characteristics of the product. Knowledge about the product is built throughout the design process with the support of digital simulation. It is important to say, that a digital prototype contains all characteristics of the product, including electrical and hydraulic / pneumatic components. This allows the view of product characteristics from a holistic perspective, including all aspects of the product.

The ability to perform simulation on the digital model benefits in fewer physical prototypes. Performance test which in the past required a physical prototype can now be done on the virtual model of the product.

Depending on the complexity of analysis the simulation tools are either embedded into the 3D CAD software or integrated of optimized exchange of data. Some 
engineers use simulation tools casually, while others specialize on advanced analysis. Engineers that leverage simulation upfront in the design process appreciate the consistent user interface of the CAD embedded product experience, while more advanced simulation capabilities lend themselves to an integrated application with direct CAD import and associatively. Figure 12 shows the different type of simulation capabilities available from Autodesk.

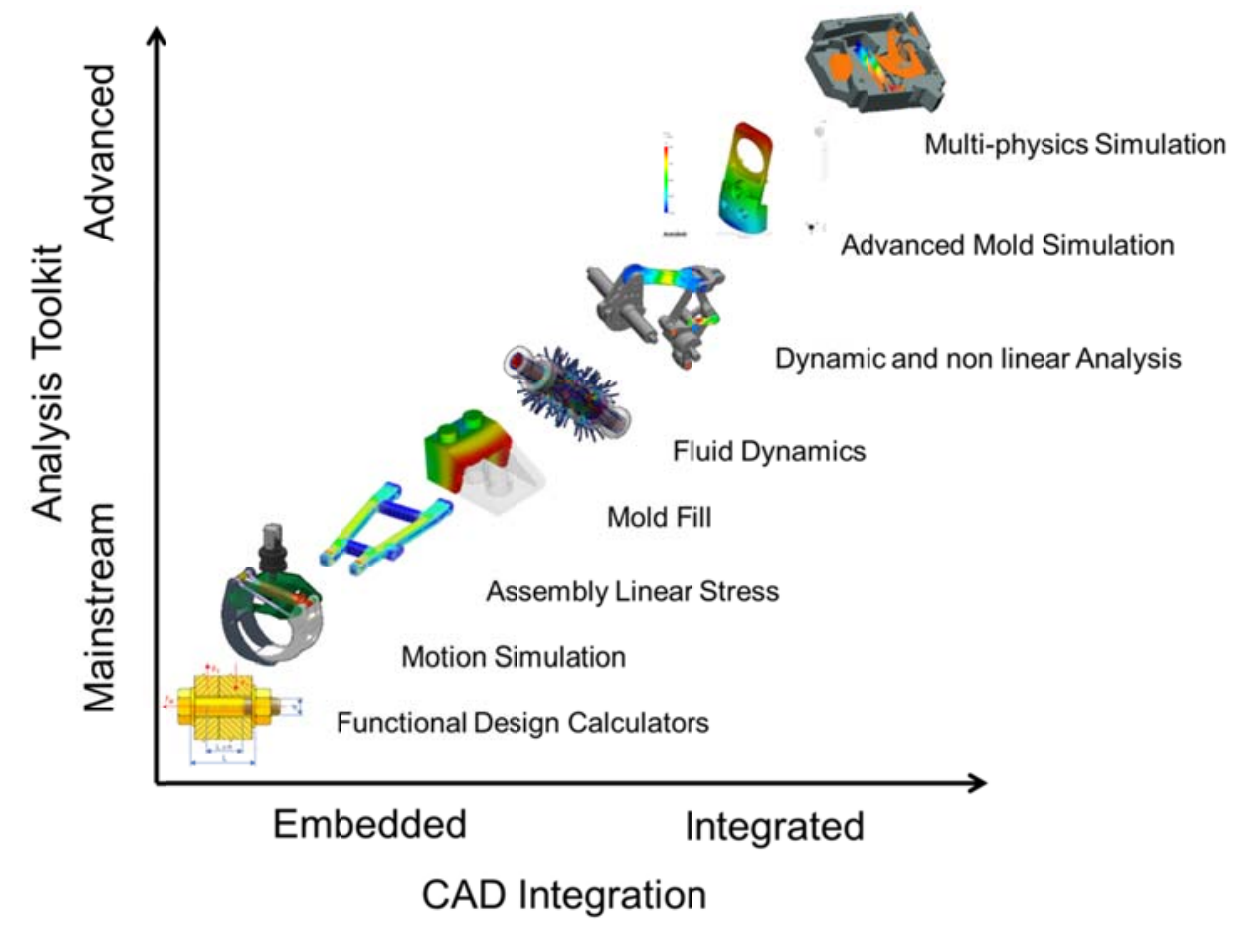

Fig. Simulation Methods with Autodesk Solutions, (Autodesk, 2010d)

Using a Digital Prototyping solution based on Autodesk ${ }^{\circledR}$ Inventor ${ }^{\circledR}$ software, help engineers design, visualize, and simulate their projects digitally and experiment earlier and more cost-effectively. (Autodesk, 2010d)

- Simulation tools such as finite element analysis help reduce and optimize the amount of materials used in the design.

- Digital Prototyping decreases the number of physical prototypes and reduces operational waste. 
During the critical concept development phase, in which designers map customer requirements into functional specification, the complexity and time to market can be mitigated by developing and composing a model of the complete product system function. The ability to evaluate alternatives earlier in the process leads into more innovative solutions that meet environmental objectives as well as improving the entire development process.

Simulation allows critical engineering decisions early in the process. Autodesk offers multiple products to study the design intent and accurately predict the performance of a digital prototype. An overview of products with simulation capabilities is shown in Figure 13.

\begin{tabular}{|c|c|c|c|c|c|c|c|c|}
\hline & \multicolumn{8}{|c|}{ Simulation Method } \\
\hline Products & 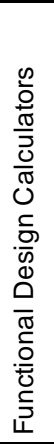 & 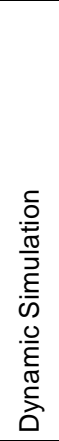 & 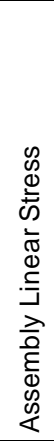 & 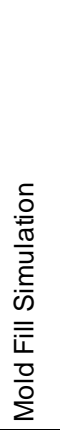 & 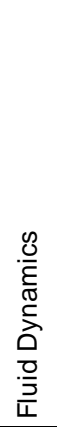 & 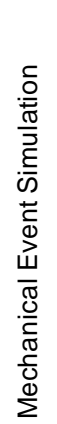 & 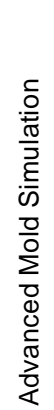 & 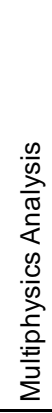 \\
\hline Autodesk ${ }^{\circledR}$ Inventor Simulation ${ }^{\circledR}$ & ○ & $\boldsymbol{\theta}$ & $\boldsymbol{\theta}$ & & & & & \\
\hline Autodesk® Inventor Tooling ${ }^{\circledR}$ & - & $\mathbf{P}$ & 0 & ( & & & & \\
\hline Autodesk $₫$ Inventor Professional ${ }^{\circledR}$ & ○ & $\boldsymbol{\theta}$ & $\boldsymbol{\theta}$ & (1) & & & & \\
\hline \multicolumn{9}{|l|}{ AutoCAD $®$ Mechanical ${ }^{\circledR}$} \\
\hline \multicolumn{9}{|l|}{ AutoCAD $\circledast$ Electrical ${ }^{\circledR}$} \\
\hline \multicolumn{9}{|l|}{ Autodesk $\circledast$ Moldflow $®$ Advisor } \\
\hline \multicolumn{9}{|l|}{ Autodesk $₫$ Moldflow $®$ Insight } \\
\hline \multicolumn{9}{|l|}{ Autodesk $\circledast$ Algor $\circledast$ Simulation } \\
\hline \multicolumn{9}{|l|}{ Autodesk® Algor® Simulation CFD } \\
\hline \multicolumn{9}{|l|}{ Autodesk® Algor $\AA$ Simulation MES } \\
\hline \multicolumn{9}{|l|}{ Autodesk® Algor ${ }^{\circledR}$ Simulation Professional } \\
\hline \begin{tabular}{l|l} 
Full functionality available \\
\cline { 1 - 1 } & Intermediate functionality available \\
\cline { 1 - 1 } & Basic functionality available
\end{tabular} & & & & & & & & \\
\hline
\end{tabular}

Fig. 13 Simulation Methods / Autodesk Products (Autodesk, 2010d) 
Topic 5.1.2 through 5.1.8 illustrates examples of various simulation types.

\subsubsection{Functional Design Calculators}

Functional Design Calculators defines the biggest group of calculation and simulation tools within the Autodesk product portfolio. In combination with geometry creation, the user is able to perform calculations for verification.

With the support of mechanical calculation, the user can ensure the design is done according to the specification in proper dimension from the very beginning. An example of calculating a bolted connection is shown in Figure 14.

The functional design calculators determine the dimensions and strength check of various mechanical elements. By utilizing standard components it enables the user to define the function before the form and leverage calculation for optimizing the mechanical components.

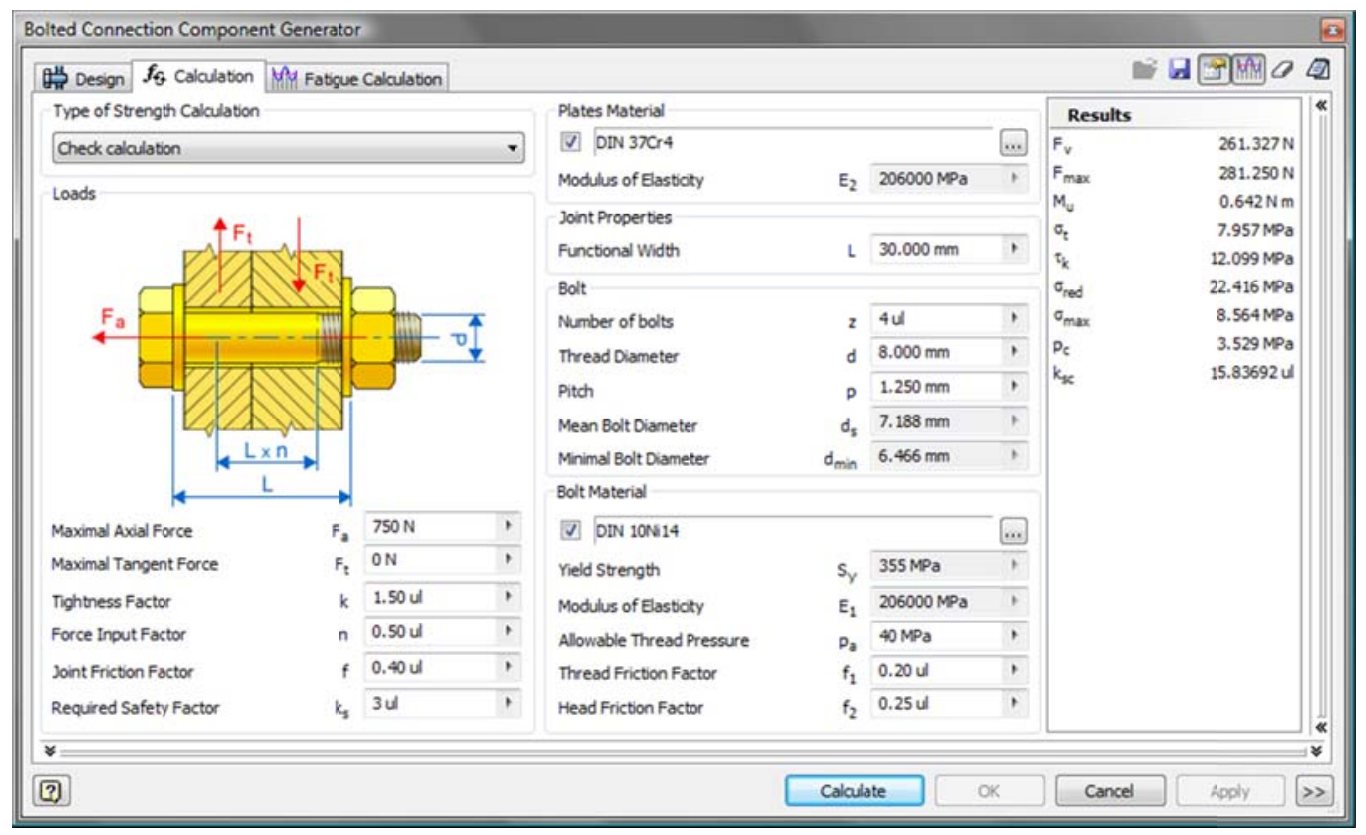

Fig. 14 Calculation for Bolted Connection (Autodesk ${ }^{\circledR}$ Inventor ${ }^{\circledR}$ ) 
Other calculation/simulation methods are:

- Gear generator (Spur, Bevel, Worm)

- Shaft generator

- Cam generator

- V-Belt, Synchronous belt generator

- Roller chain generator

- Key connection

- Frame Generator

- etc.

\subsubsection{Dynamic Motion Simulation}

Dynamic motion simulation includes static and modal finite element analysis (FEA) of parts, assemblies and load-bearing frames.

\subsubsection{Assembly Linear Stress Simulation}

Finite element analysis helps reduce and optimize the amount of materials used in the design. Digital Prototyping decreases the number of physical prototypes and reduces operational waste.

\subsubsection{Mold fill simulation}

The mold fill simulation includes plastic simulation tools to validate the design of injection molds for plastic parts. By simulating the injection mold process, alternative material candidates are evaluated.

The creation of injection-molded plastic parts is a complicated process that can lead into unexpected delays and increased costs. Mold fill simulation is used to simulate the fill behavior of plastic parts during the injection molding process. Mold cooling simulation improves the cooling system efficiency, minimize part warpage, and achieve smooth surfaces. The choice of material has a critical impact on the product's environmental quality. 


\subsubsection{Fluid dynamics and heat transfer analysis}

With fluid dynamics, detailed fluid flow behavior and the thermal characteristics of the product design is simulated. To avoid product failures, heat transfer analysis provide insights to a product's temperature profile. Heat flow and heat flux can be identified when temperature or loads vary over time. Energy efficiency in fluid systems as well as improvements on efficiency for heat transfer systems and incorporate thermal energy recovery systems are some benefits of fluid dynamics and heat transfer analysis.

\subsubsection{Mechanical event simulation}

Design decision can be enhanced with accurate simulation by using multi-body dynamics with the support of large-scale motion, large deformation, and large strain with body-to-body contact.

\subsubsection{Advanced Mold simulation}

In addition to regular mold fill simulation, advanced mold simulation provides simulation of state-of-the-art process applications such as gas-assisted injection molding and co-injection molding. This includes predictions how molds will fill with or without fiber-reinforced pre-forms. Simulating the most advanced injection molding processes predicts and corrects part defects and optimizes the part and mold designs.

\subsubsection{Multiphysics analysis}

Multiphysics analysis allows the study of result from multiple physical factors acting simultaneously. By combining the results from different analysis, real-world product performance can be predicted.

- Fluid and Thermal Analysis

- Thermal Stress Analysis

- Fluid and Structural Analysis

- Electrostatic Analysis

- Joule Heating Analysis

- Electromechanical Analysis 


\subsection{Designing environmental friendly plastic products}

Designing plastic components for injection molding is a highly complex and demanding task that involves designers, plastic material specialists, engineers and tool makers. Full collaboration by the experts is required to realize the benefits of an environmental friendly product. Also, the process of injection molding involves high tooling costs and demands high volumes in order to be cost effective.

Material selection is primarily based on the physical and mechanical requirements of a product and their characteristics have obviously a significant effect on environmental issues. The embodied energy consumption for the plastic material varies drastically depending on the selected vendor and has a main influence on the environmental impact of the product.

Plastic material selection criteria from an environmental perspective are (Autodesk, 2010b):

- Carbon footprint - material with lower carbon reduces the generated $\mathrm{CO} 2$

- Embodied energy - material with lower embodied energy reduces the energy requirements

- Embodied water - material with lower embodied water lessens water resources required

Autodesk provides with Autodesk ${ }^{\circledR}$ Moldflow ${ }^{\circledR}$ software a comprehensive set of tools for validating and optimizing plastic parts and the mold injection process. Manufacturers can evaluate various material candidates and helps to predict the flow behavior of melted plastics to achieve higher-quality manufacturing and sustainability requirements. 


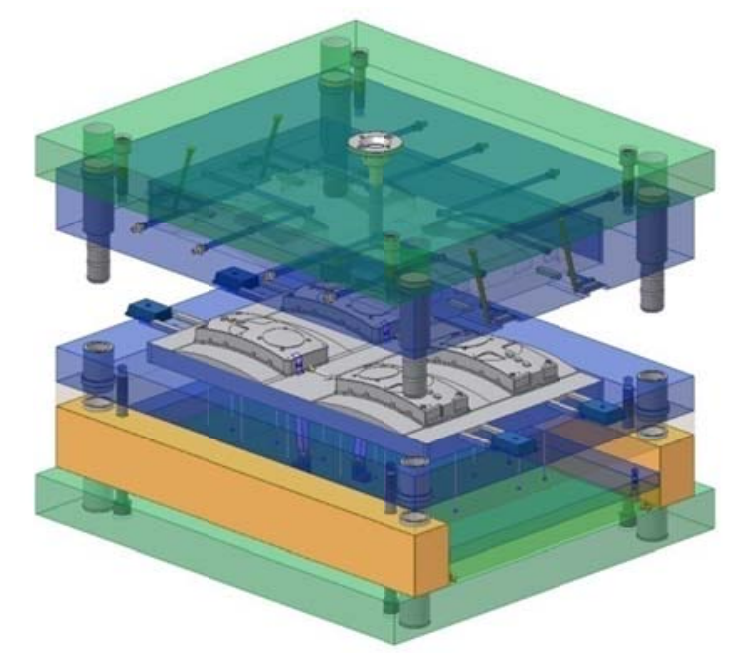

Fig. 15 Mold base (Autodesk ${ }^{\circledR}$ Inventor ${ }^{\circledR}$ Tooling)

Potential manufacturing defects can be predicted before mold tooling is cut (Figure 15 Mold base, created in Autodesk ${ }^{\circledR}$ Inventor ${ }^{\circledR}$ Tooling). Also with state-of-the-art plastic material testing services, Autodesk supplies energy usage indicators and material recommendation wizards enabling designers to reduce energy requirements and choose the most sustainable material for their project.

From environmental perspective, following areas can be identified for potential improvements by mold fill simulation with Autodesk ${ }^{\circledR}$ Moldflow ${ }^{\circledR}$ software:

\subsubsection{Exploring environmentally friendly materials}

There are many developments that reduce the environmental impact of plastics. Disposable products are produced in bioplastics or thermoplastics with bioactive additives. Autodesk ${ }^{\circledR M o l d f l o w}{ }^{\circledR}$ software comprises of a material library with properties of more than 8000 plastic materials.

While environmental friendly materials are often too narrowly considered because of the financial risk involved by potentially production failures, a manufacturer is able to explore and compare alternative material selection and simulate to understand the effect on engineering. It identifies the best material that meets functional and performance needs as well as sustainability alternatives. 
Figure 16 and 17 illustrate selection criteria for the plastic family and energy usage indicator. With this classification, plastic materials are categorized and various alternatives can be searched and compared to choose the most sustainable material for the project. (Figure 18)

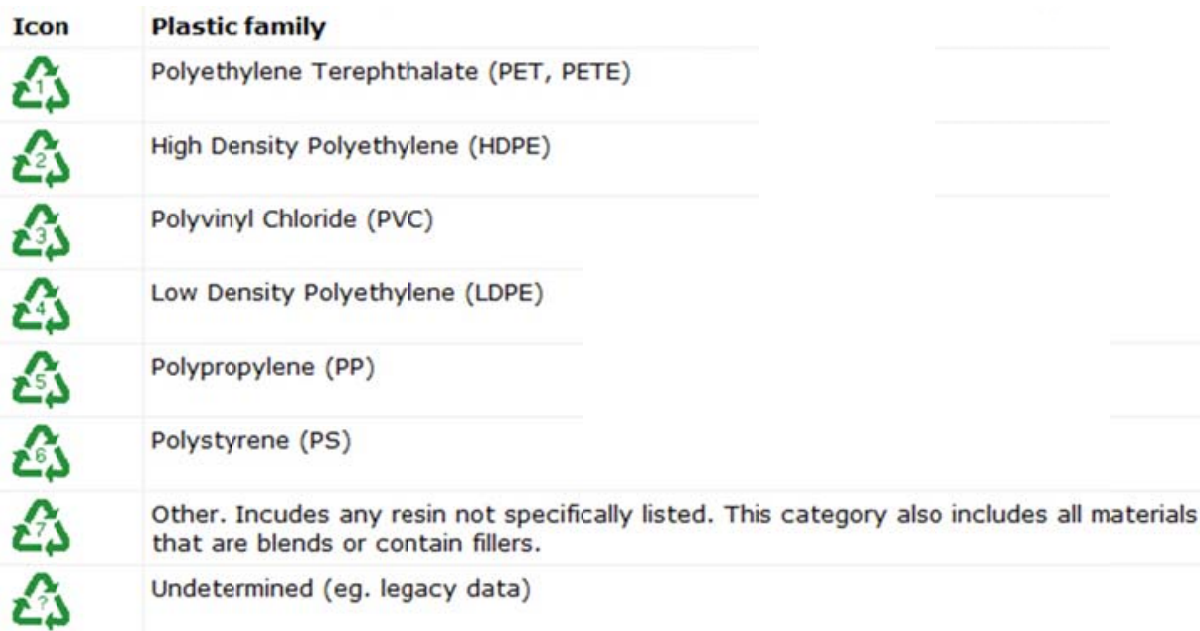

Fig. 16 Selection of plastic family (Autodesk ${ }^{\circledR}$ Moldflow ${ }^{\circledR}$ )

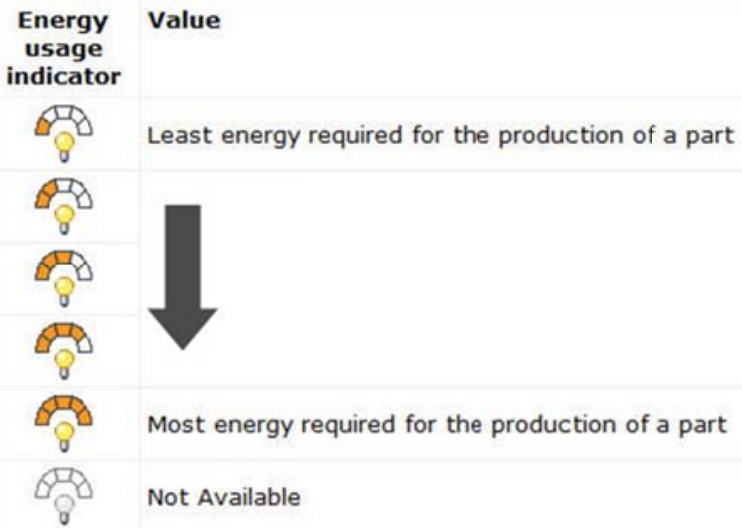

Fig. 17 Energy usage indicator (Autodesk ${ }^{\circledR}$ Moldflow ${ }^{\circledR}$ ) 


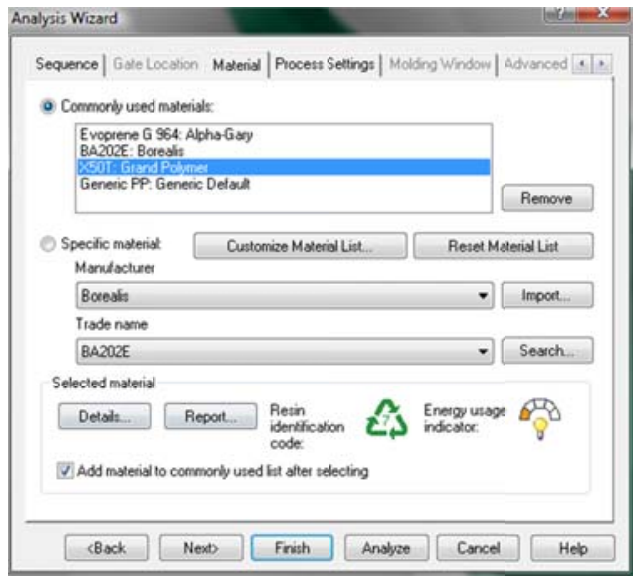

Fig.18 Comparison of materials (Autodesk ${ }^{\circledR}$ Moldflow ${ }^{\circledR}$ )

\subsubsection{Material Reduction}

Beside the product characteristics, there are a number of considerations from a mold feature perspective during the design phase of a plastic product. Optimizing gate runner location or improved cavity layout are ways to reduce the amount of material required. A plastic part should ideally have an even wall thickness across the entire part. Mold fill simulation is able to provide suggestions and optimize the plastic part for material reduction.

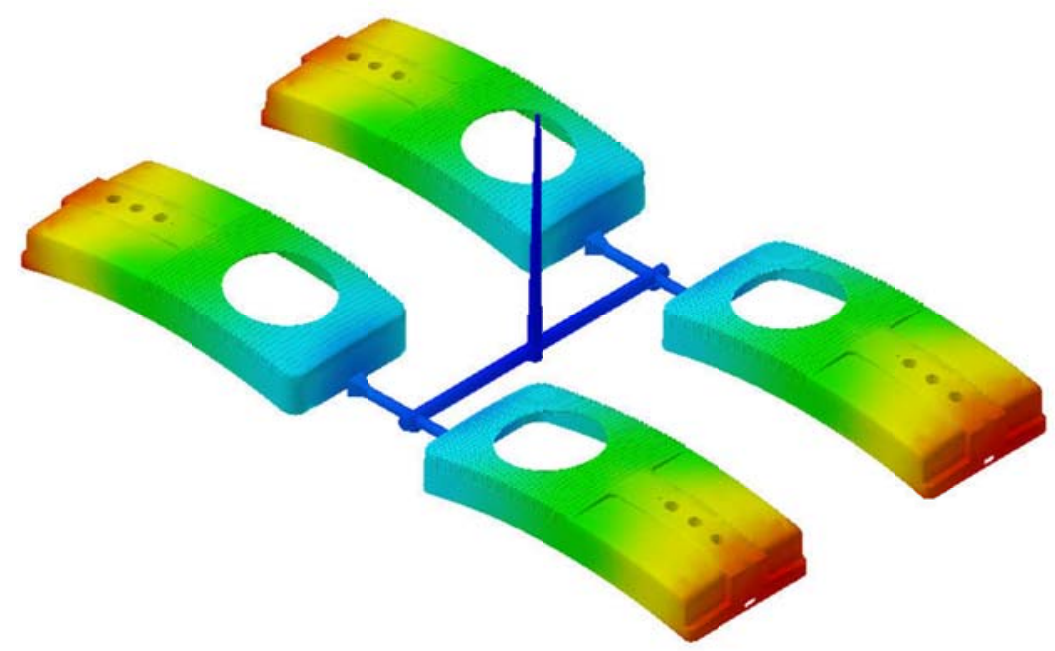

Fig. 19 Mold fill analysis (Autodesk ${ }^{\circledR}$ Moldflow $\left.{ }^{\circledR}\right)$ 


\subsubsection{Thermoplastic Scrap Reduction}

Thermoplastic scrap can be directly recycled in the process of injection molding. Some applications, such as food packaging and medical devices require a high level of virgin material, whereas garden furniture may require less virgin material for adequate structural, hygiene and coloring capabilities.

If there are different types of materials used, considerations for easy disassembly are important. Snap fit or other mechanical fastener can improve the disassembly of components and facilitate the dispose of parts with minimal environmental impact. (Anastas and Zimmermann, 2007)

\subsubsection{Recycle Existing Resources}

Because of the high tooling costs involved in injection molding increased lifetime of the molding can significantly reduce costs and therefore the environmental impact. In some cases the life-time of existing tooling can be extended by adoption of existing molds.

\subsubsection{Product Durability}

By considering the optimization of plastic component better predictions can be made to the stability and end-of-life of a product. Often excessive part failures are faced due to high mechanical forces. By redesigning the part using different materials or additives (e.g. fiber filled plastic) the product life can be significantly improved.

\subsubsection{Energy consumption involved in the production process}

Optimizing the part design and runner system for a mold has direct impact on the clamp tonnage. The lower the clamp force, the less energy is needed. Injection pressure and clamp force can significantly influence the energy consumption. The mechanical properties of a material play a major role influencing requirement for clamping force and therefore energy consumption. 
Topic 5.3 through 5.3.3 illustrates examples of various types of mold analysis.

\subsection{Mold fill time analysis}

The fill analysis predicts the thermoplastic polymer flow in the molding process, helping to foresee the behavior of the material as it flows through the cavity. A detailed simulation of the material behavior is vital when evaluating alternative materials to ensure the material is suitable for the injection mold fill process.

The fill time result in figure 20 shows the flow path of the plastic through the model. All regions with the same color are filled at the same time. In a part with a good fill time result, flow pattern is balance meaning all flow paths finish at the same time and contours are evenly spaced.

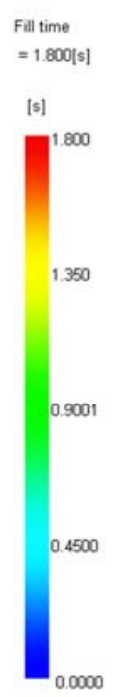

Autodesk

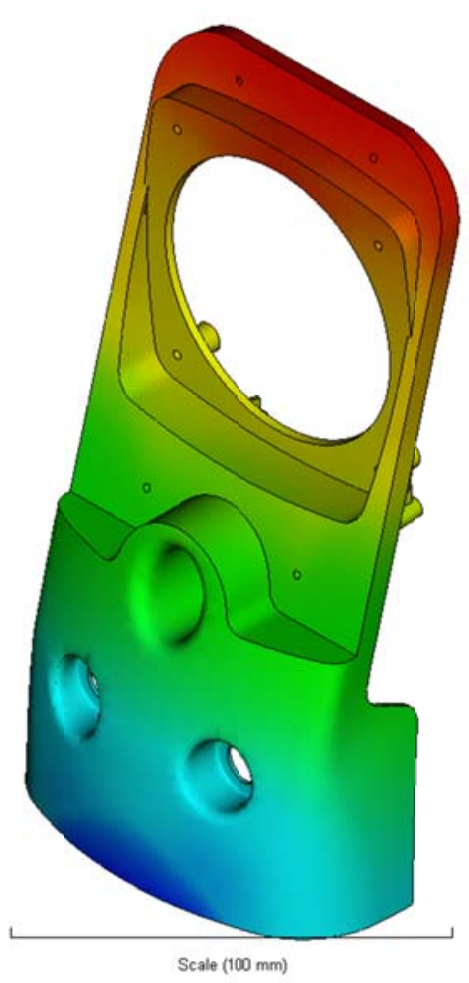

Fig. 20 Injection mold fill time analysis (Autodesk ${ }^{\circledR}$ Moldflow ${ }^{\circledR}$ ) 


\subsubsection{Elimination of shrink marks}

Simulation results in Autodesk ${ }^{\circledR}$ Moldflow ${ }^{\circledR}$ software allow determination on how well a part design will fill with plastic material. It identifies the defects such as sink marks and part warpage. By simulation of the various gate positions and runner system configurations the stress can be reduced and defects can be avoided before the product has been built.

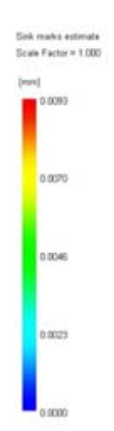

Autodesk

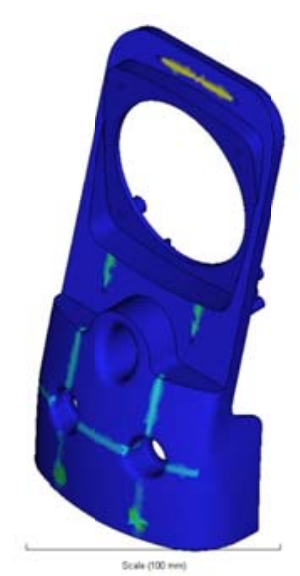

Fig. 21 Injection mold sink mark analysis (Autodesk ${ }^{\circledR}$ Moldflow $\left.{ }^{\circledR}\right)$

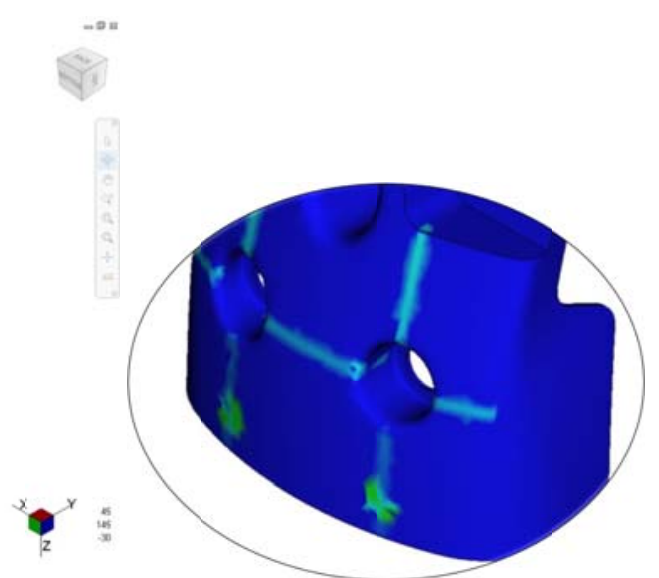

Autodesk ${ }^{\circledR}$ Moldflow ${ }^{\circledR}$ software increases the use of regrind, recycled and biodegradable plastic resins in product designs. Reducing the material content in plastic part design while ensuring part can be manufactured \& have maximum quality. 


\subsubsection{Photorealistic defect visualization}

It may be difficult to judge the impact of defects based on the analysis. By exporting analyze results into Autodesk ${ }^{\circledR}$ Showcase ${ }^{\circledR}$ defects are photo realistically visualized. Different material textures can reduce the defect. With use of a different material instead of high glossy surface treatment, the effect of a shrink mark defect may be reduced. Figure 22 displays shrink marks on a high glossy material compared to figure 23 with textured material. Better visibility into surface defects reduces the need for vinyl decals and paint, which increases the recyclability of the part.

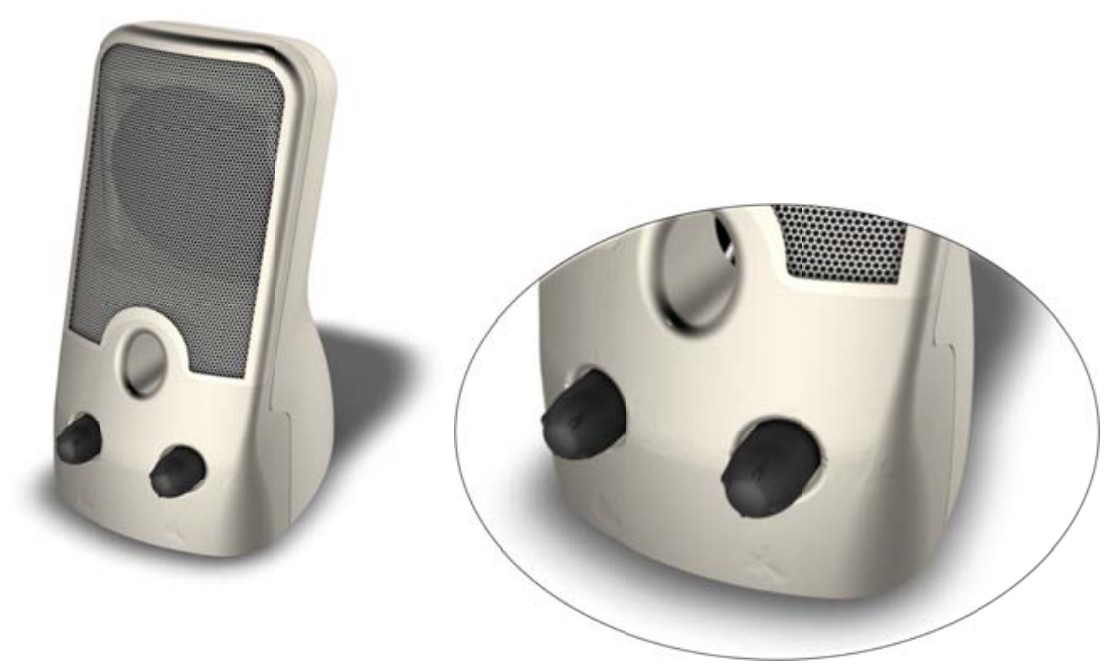

Fig. 22 Photorealistic defect visualization selection (Autodesk ${ }^{\circledR}$ Moldflow ${ }^{\circledR}$; Autodesk ${ }^{\circledR}$ Showcase ${ }^{\circledR}$ )

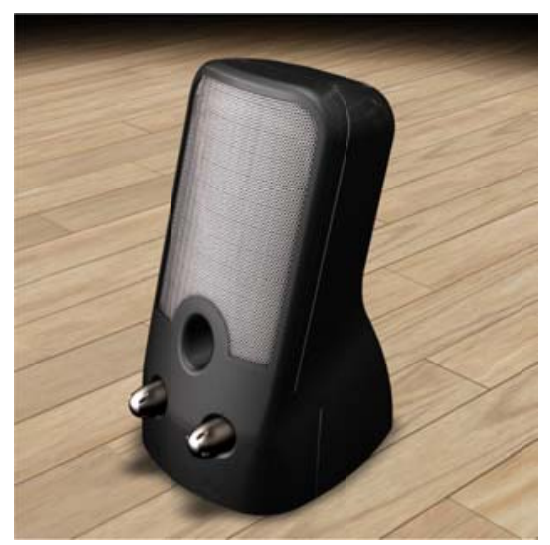

Fig. 23 Photorealistic defect visualization with alternative material selection (Autodesk ${ }^{\circledR}$ Moldflow ${ }^{\circledR}$; Autodesk ${ }^{\circledR}$ Showcase ${ }^{\circledR}$ ) 


\subsubsection{Design Adviser}

A Design Adviser analysis shows areas in the part that are likely to cause problems during the injection mold process. The geometry is analyzed for potential issues with draft angle, undercuts and nominal wall thickness. Fig. 24 displays thickness variations relative to the wall thickness of the part.

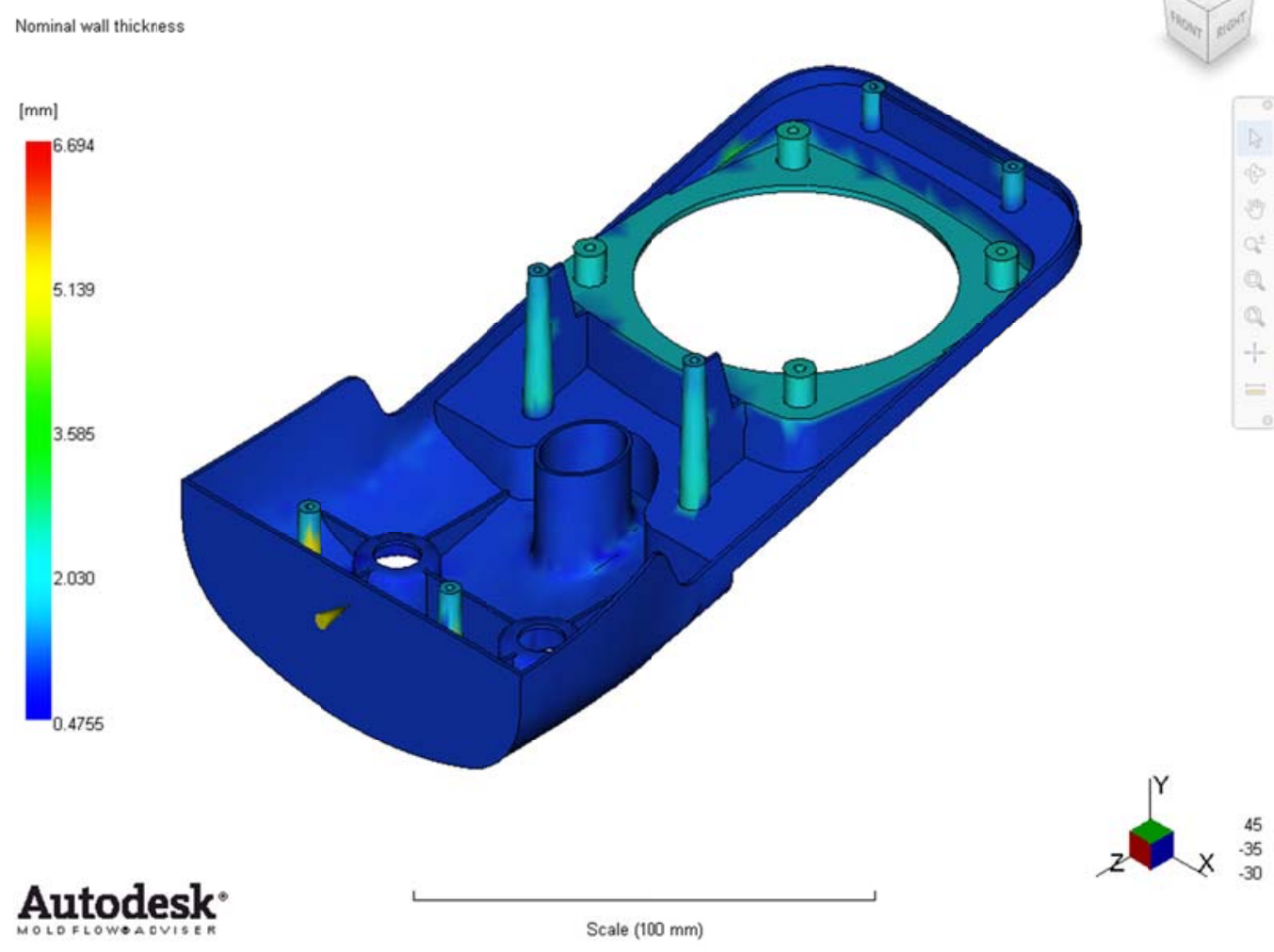

Fig. 24 Nominal wall thickness analyze (Autodesk ${ }^{\circledR}$ Moldflow $\left.{ }^{\circledR}\right)$

Optimizing the plastic part design by using design adviser functionality provides opportunities for material reduction. Mold fill simulation is able to provide suggestions and predict the impact of various thermoplastic resin options. 


\subsection{Real time feedback for plastic components design}

Mold fill simulation can provide information to take corrective actions on the model for improving the manufacturing process and reducing the environmental effect. However, some of the issues identified in the simulation process can be avoided already during the part detail design. (Autodesk, 2010a)

Autodesk provides with project Krypton an add-on to Autodesk ${ }^{\circledR}$ Inventor ${ }^{\circledR}$ for realtime feedback on a plastic part's manufacturability, cost efficiency, and the environmental impact of the selected material (Autodesk, 2010a). The add-in is currently available as technology preview for testing purposes. http://labs.autodesk.com/utilities/krypton/

During the design work, the plastic part is measured against various design characteristics. The user receives advice to ensure the product can be properly manufactured, and is produced using materials with a lower environmental impact. Design concerns are identified already during the design phase and can be corrected as the user is working on the geometric extents of the model (Fig. 25, Performance indicator gauge)

There are three factors measured during the design work:

- Manufacturability indicator

- Cost efficiency indicator

- Plastic material impact indicator

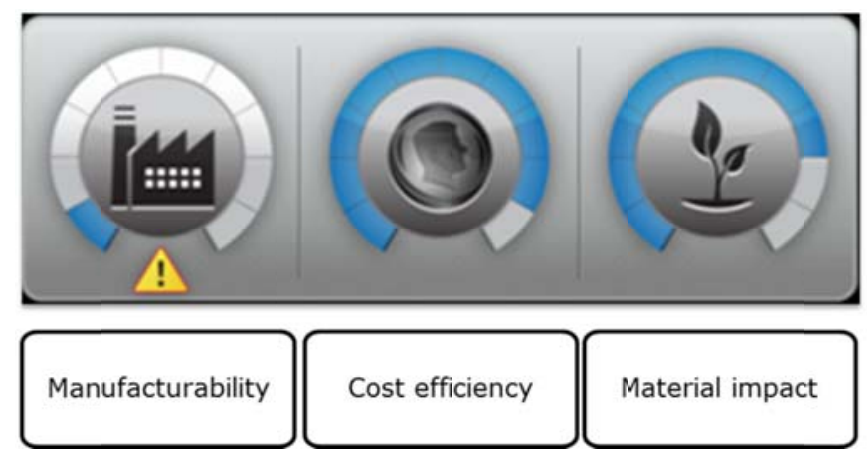

Fig. 25 Performance indicator gauge, (Autodesk, 2010a) 
The user can review details of each problem and view difficult areas highlighted directly on the model. Design advice is offered, which helps the user to make appropriate design changes to address the concerns. While the manufacturability and cost indicator have an indirect implication on the environmental influence, the display of the plastic material indicator directly controls the environmental impact.

Autodesk, (2010b) describes the various indicators and how plastic part design is influenced by them.

\subsubsection{Manufacturability indicator}

Manufacturability is a combination of the following:

- Ease in which the part is processed

- Likelihood of defective parts

\section{Draft angle}

A draft angle is a slight taper added to surfaces to assist in the ejection of the molded part from the mold. (Figure 26 Draft angle analyze) Surfaces parallel to the direction the part is ejected in will cause difficulties in production. The amount of draft added will depend on the material to be used and the surface finish of the part.

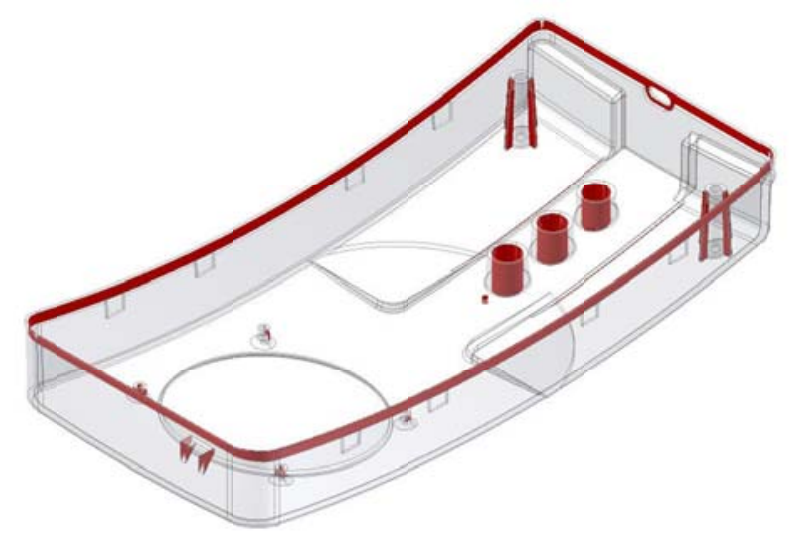

Fig. 26 Draft angle analyze (Autodesk ${ }^{\circledR}$ Inventor ${ }^{\circledR}$; Project Krypton

\section{Processability}

The processability of the design is a combination of several factors which includes the following: 
- Ease with which the part is processed

- Likelihood of defective parts

- Production rates and cycle times

- Range of processing parameters that will produce a good part

\section{Undercuts}

An undercut is a design feature that interferes with the ejection of a formed part from the mold. An undercut can include features such as holes or bosses that are not aligned with the direction of ejection, threaded sections, and snap fingers.

\section{Wall thickness}

Ideally, a plastic part should have an even wall thickness across the entire part otherwise quality problems can occur. The thickness also defines the filling and cooling of the part. Molten plastic will prefer to flow through thick sections of the mold so excessively thin areas may have problems filling. Excessively thick areas will take longer to cool which may lead to the part deforming as the molten plastic solidifies. The wall thickness indicator examines the part thickness and Manufacturability indicator.

\subsubsection{Cost efficiency indicator}

Cost efficiency indicator is a combination of the following contributing factors:

- Material cost

- Mold cost

- Production cost

\section{Material cost}

The Material cost depends on a range of factors. Some of the characteristics considered when determining this value include the following:

- Volume of the part

- Number of gates and the volume of the associated feed system 
- A projected scrap rate based on how the material processing

- characteristics

- Cost of the material

\section{Mold cost}

The cost to produce a mold depends on a range of factors. Some of the characteristics considered when determining this value include the following:

- The size, volume and complexity of the part

- Number of gates and the associated feed system

- Extent and type of undercuts required

\section{Production cost}

The production cost depends on a range of factors. Some of the characteristics considered when determining this value include the following:

- Part cooling time

- Total machine cycle time

\subsubsection{Plastic material impact indicator}

Different plastic material families have different characteristics and applications. Autodesk project Krypton provides an initial guide to selecting an appropriate material, and enables the design engineer to make sensible choices (Autodesk, 2010a).

Plastic material impact is measured by a combination of the following considerations:

- Emissions (i.e. carbon footprint)

- Energy usage

- Water usage

- End of life (i.e. recyclability) 


\section{Emission}

The carbon footprint is a measure of the amount of $\mathrm{CO} 2$ gas produced by the production of the selected material.

\section{Embodied water}

Embodied water is a measure of the amount of water required to produce the selected material.

\section{Recyclability}

The recyclability of a material is a measure of the percentage of the material that is recovered as scrap and subsequently reprocessed into useful products. 


\subsection{Meet the needs with Optimization}

In absence of analysis, engineers usually go for the save choice in their design. From safety viewpoint, this may be the right choice but the over-engineered design results in unnecessary bounded resources from material and also process perspective. An important principle in reducing the environmental effect is to use less material wherever possible. (Anastas and Zimmermann, 2007; Willis, 2009)

Organizations are striving to reduce the impact of their consumption patterns on the environment. This is known as dematerialization. Originally, dematerialization is conceived as an approach to reduce the weight of materials used in manufacturing. Gordon, (2001) points out improving resource productivity by process improvements in all value-adding activities.

A way to avoid superfluous material is to check stresses with the help of FEA calculation to identify areas where material can be removed. The FEA calculation is usually done on a given maturity state of the model and is a static process. Depending on the situation this may be done in a state of early concepts or when a full 3D model is available. Preferably, simulation is done in the early stages of the design.

One of the advantages in 3D parametric design is the way modifications are done on the model. By changing parameter values, the model can be adapted in size, shape, material and color. FEA calculation provides feedback on the stresses within the 3D model and parameters can be optimized for a range of values to get the best result while still maintaining the required safety factors.

The limitations with the optimization approach come with the complexity of the model. As soon as the numbers of parameters grow, which are considered for the optimization, multiple configuration of the FEA model need to be calculated. Each combination results in another configuration for calculating the FEA model. 
The calculation of complex models is very processor intensive and can be time consuming. Autodesk, (2010c) points out, new technologies such as cloud computing can be beneficial to reduce the processing time, since it enables the user to work in parallel by offloading time consuming computations to web services.

\subsubsection{Optimization of multiple parameters}

Autodesk recently announced a new web based service, called Inventor ${ }^{\circledR}$ Optimization, as a technology preview (http://labs.autodesk.com) for optimization of 3D CAD models. (Autodesk, 2010c)

The Inventor ${ }^{\circledR}$ Optimization Technology Preview allows designers and engineers that use Autodesk ${ }^{\circledR}$ Inventor ${ }^{\circledR}$ to optimize their designs. It is a simple, web-based simulation tool to help an engineer minimize weight and cost while improving product safety.

A 3D model is optimized based on a number of parameter values. In a 3D model, multiple calculations are combined into an optimization model and checked for validity. The calculations are offloaded to a set of web services that provide resizable dynamic computational and data storage capabilities via the internet ("The cloud"). The user can continue to work in parallel without any performance degradation. Once the optimization is finished the user gets automatic notification by email.

Leveraging additional processing resources offered by the cloud service allows the user to do multiple design configurations in parallel. Computations can be done in less time and without excessive hardware requirements. The cloud is a reference to a set of web services that provide resizable dynamic computational and data storage capabilities that can be accessed via an internet connection. 


\subsubsection{Set up for optimization}

The analysis is showing that the model is statically and dynamically stable and free from divergence on application of external loads and frequencies. In this optimization, we are using stress analysis to ensure that the material and geometry of the gripper can handle the loads without deforming and failing. All objects have a stress limit depending on the material used, which are presented as material yield. (Figure 27 Parametric model of crane gripper)

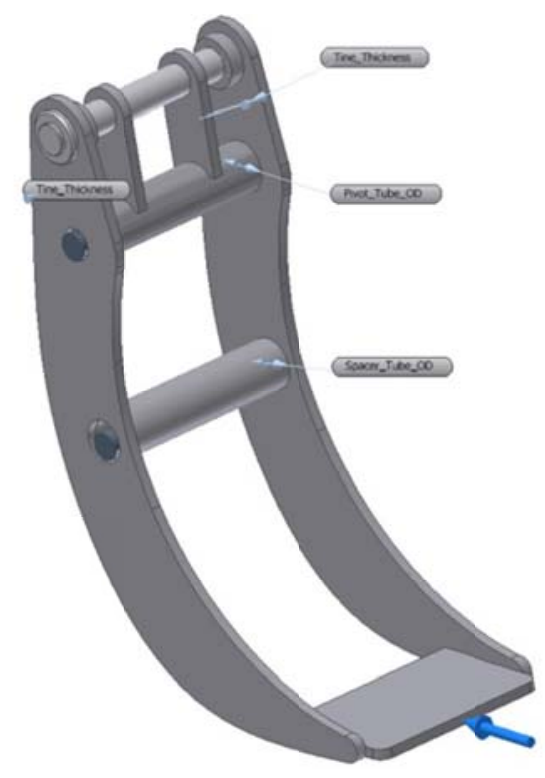

Fig. 27 Parametric model of crane gripper (Autodesk ${ }^{\circledR}$ Inventor ${ }^{\circledR}$ Software, Inventor Optimization Technology Preview)

In the example of the crane gripper there are three parameters with three distinct values as shown in table 3 .

Table 3 Parameter-Value table for optimization

\begin{tabular}{|c|c|}
\hline Parameter & Values \\
\hline Pivot_Tube_OD & $46,48,52$ \\
\hline Spacer_Tube_OD & $46,48,52$ \\
\hline Tine_Thickness & $9,10,11$ \\
\hline
\end{tabular}


The number of parameters and possible values provides a total number of 27 different combinations. Figure 28 shows the safety factor results of the optimal configuration.

\subsubsection{Optimization Result Summary}

The optimization results in a combination of parameters for an enhanced weight of the product. Table 4 indicates the physical properties and potential weight reduction of the optimized configuration.

\section{Table 4 Optimization results}

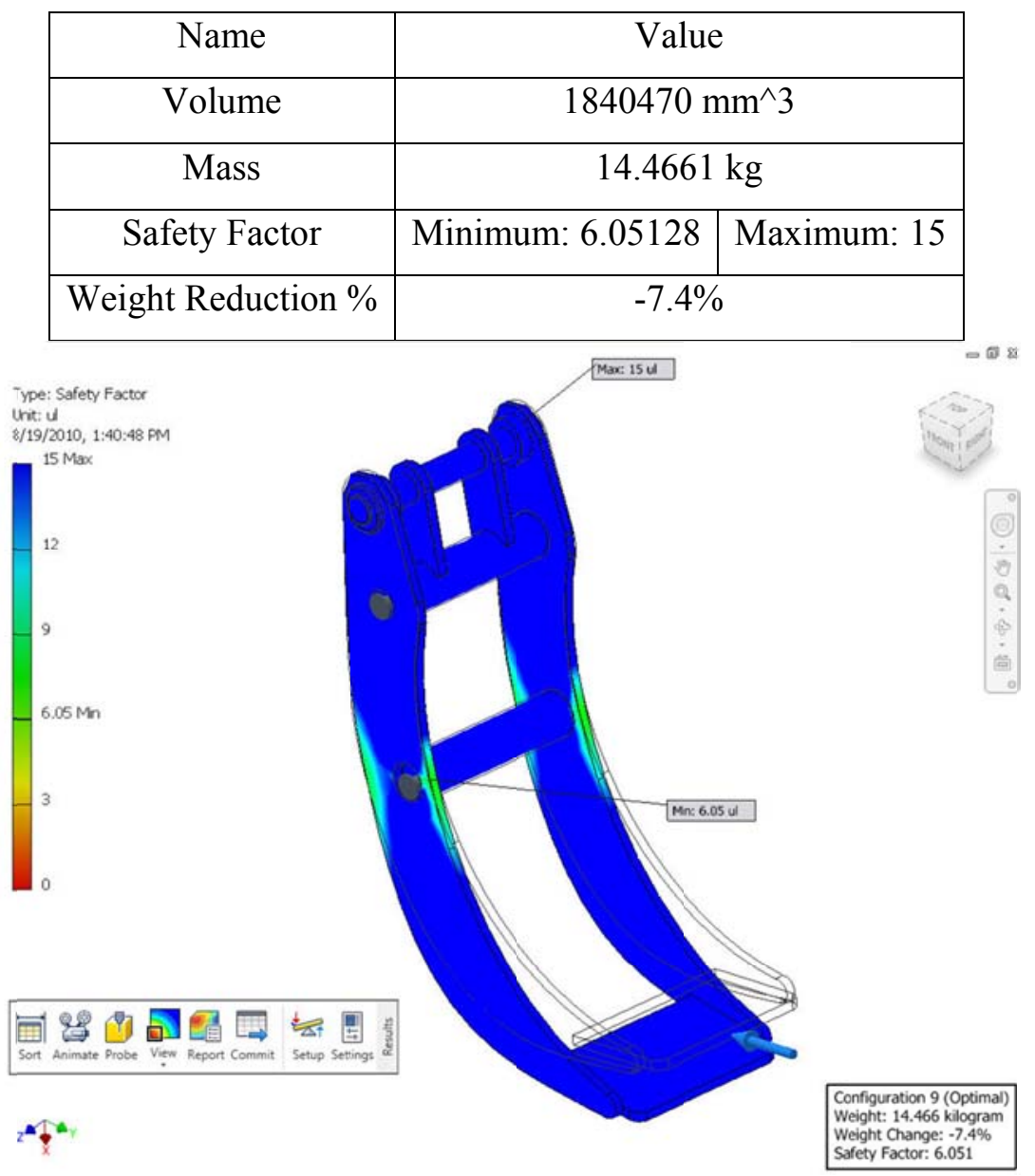

Fig. 28 Optimization results (Autodesk ${ }^{\circledR}$ Inventor ${ }^{\circledR}$ Software, Inventor Optimization Technology Preview) 
Based on the 27 possible configurations, 18 meet the needs of a safety factor. Nine of them failed and are not considered as possible solutions. (Figure 29)

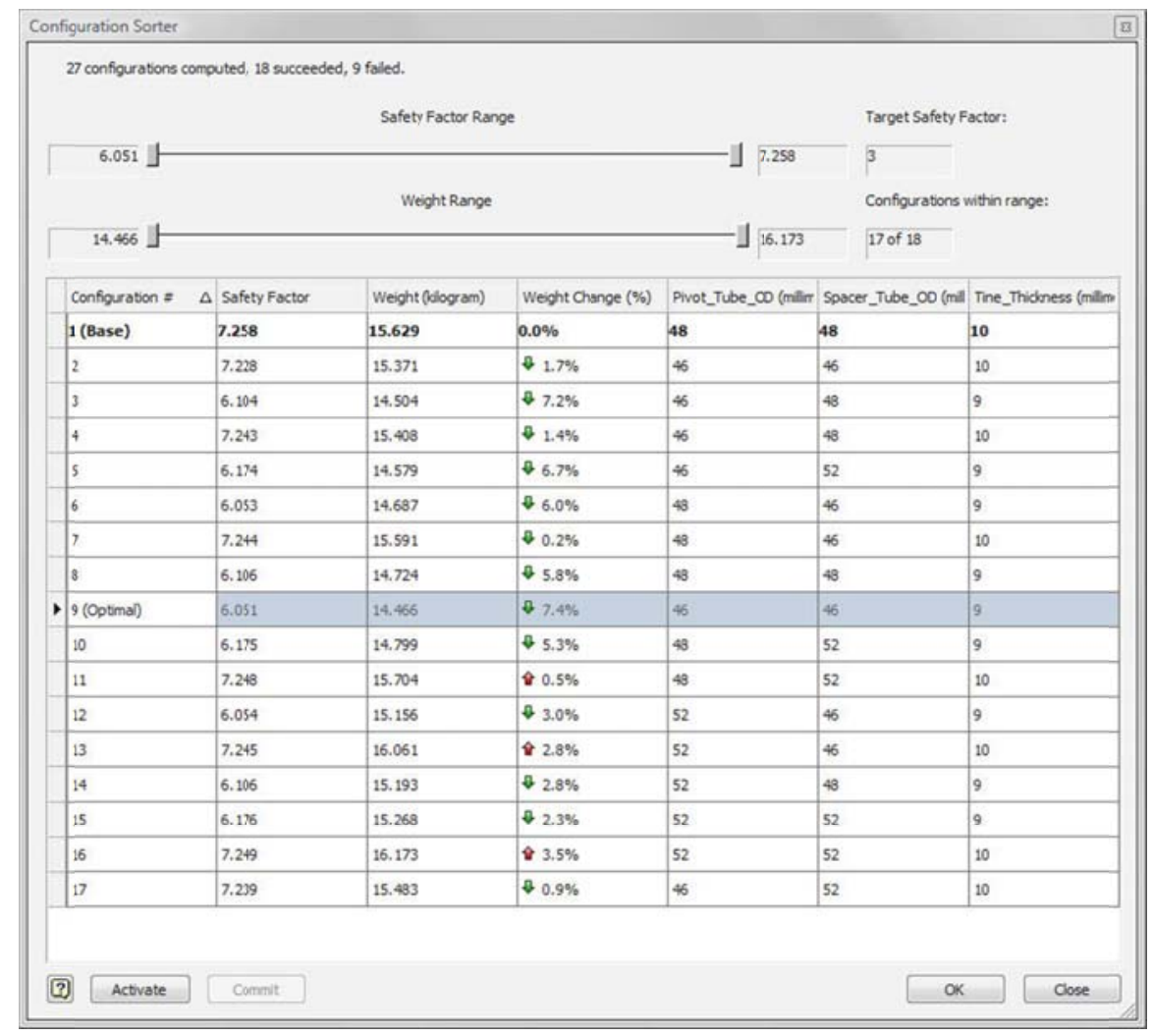

Fig. 29 Optimization results (Autodesk ${ }^{\circledR}$ Inventor ${ }^{\circledR}$ Software, Inventor Optimization Technology Preview)

The displayed example shows a method for de-materialization while still maintaining the required safety factor. Unlike traditional FEA calculation methods, where each configuration is calculated after another, Autodesk ${ }^{\circledR}$ Inventor ${ }^{\circledR}$ Software and the Inventor Optimization Technology Preview enables the user to analyze multiple configurations at the same time. 


\subsection{Durability simulation}

One way to determine the durability performance of a product is to run an endurance test using a physical prototype. The cost associated to such test is obvious. First, the physical prototype needs to be manufactured and secondly the durability test needs to be done, mostly over a longer period of time. This can take up to multiple months. Not only that there is a high cost involved of doing such, the time delay has significant impact on the time to market. Durability simulation can be brought to a virtual environment with Autodesk ${ }^{\circledR}$ Algor ${ }^{\circledR}$ software.

\subsubsection{Fatigue Analysis}

Autodesk ${ }^{\circledR}$ Algor ${ }^{\circledR}$ uses a wizard interface to guide through the steps required to perform complex fatigue analysis-vital for products such as steel rails, beams, girders, and rotating stepped shafts that can experience mechanical failure under repeated or varying loads.

Basic fatigue analysis for bolted connection is also accessible in Autodesk ${ }^{\circledR}$ Inventor ${ }^{\circledR}$ (Figure 30).

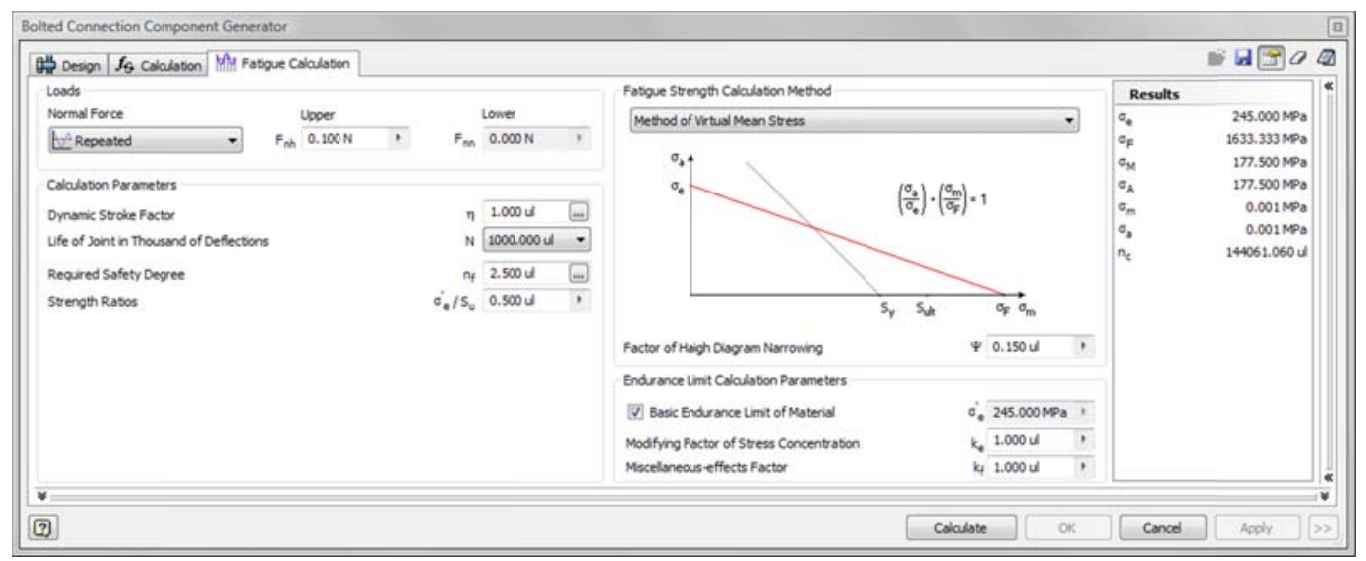

Fig. 30 Fatigue calculation for Bolted Connection (Autodesk ${ }^{\circledR}$ Inventor ${ }^{\circledR}$ ) 


\subsubsection{Contact test (drop test)}

A drop test is a technique for measuring the durability of a part or material by subjecting it to a free fall, from a predetermined height to a surface, under prescribed conditions.

The interaction and transfer of loads can be accurately simulated between multiple parts of an assembly, for both linear and nonlinear contact scenarios. Autodesk $\mathbb{}$ Algor ${ }^{\circledR}$ Simulation software supports bonded, welded, free/no, surface, and edge contact. Nonlinear contact includes additional contact methods such as coupling elements, dashpot elements, and surface-to-surface contact. Surfaces and parts are specified that may come into contact throughout an event. 


\subsection{Disassembly documentation for recycling}

At end-of-life, certain products require disassembly before they can be moved to the secondary market or recycled. In many cases the disassembly process is a highly manual process. For dismantlement, the order and method of disassembling can determine the design. Interferences and difficulties in disassembly can be avoided in creating disassembly instructions. The challenge of taking a product apart depends on the complexity and connecting methods of parts in the product. Assembly and disassembly documentation is usually done within the 3D CAD package. In addition, Autodesk proposes the use of Autodesk ${ }^{\circledR}$ Inventor ${ }^{\circledR}$ Publisher for assembly and disassembly documentation. By extending the reach to product documentation teams, workload for the design engineers can be reduced. 3D CAD data is leveraged for repair instructions and disassembly instructions. The associative update to the Autodesk ${ }^{\circledR}$ Inventor ${ }^{\circledR} 3 \mathrm{D}$ design model allows the definition of the disassembly documentation in an early design stage to identify potential disassembly interferences before the design is too advanced. For optimization on disassembly, the digital model simplifies the analysis.

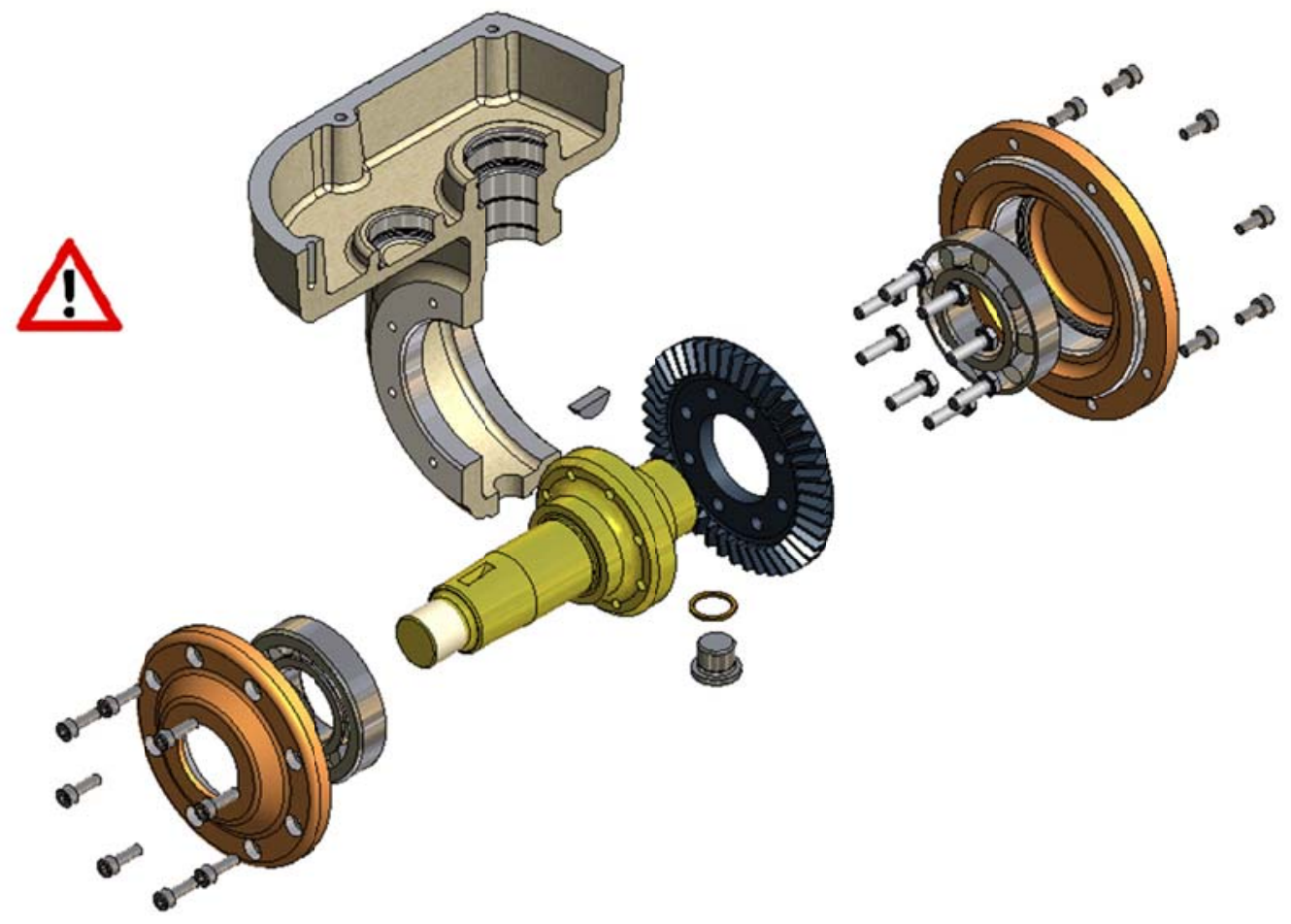

Fig. 31 Assembly documentation (Autodesk ${ }^{\circledR}$ Inventor ${ }^{\circledR}$ Publisher) 


\subsection{Simulation of energy loss}

Products are becoming increasingly more complex and manufacturers are using a mechatronics based approach to integrate electronic, mechanical and software components. The integrated approach provides new capabilities in analyzing energy loss in mechatronic systems.

Autodesk provides with AutoCAD ${ }^{\circledR}$ Electrical ${ }^{\circledR}$ software, which estimates in the area of power conductor size versus energy losses. Designing to meet minimum code requirements can conflict with environmental design.

For example, designing to the minimum conductor size for a given load can provide short-term savings on material cost but run up longer-term expense due to higher heating losses in the wiring. Over the life of the installation, the energy loss in heating up the minimum-sized wiring, instead of reaching the load to do useful work, could be substantial.

During wire sizing, a list of the valid wire sizes meeting the ampacity requirements of the load is displayed, and also a list of the estimated maximum energy loss cost for each wire size. This set of calculations allows better environmental design decisions.

For example, if the conductors for a motor are oversized, heat losses will be reduced. This results in a higher initial cost for material and installation labor. However, this cost is recovered many times over in reduced energy losses in the wiring during the life of the installation.

For reducing energy waste, the entire life-cycle of a product needs to be considered and taken into account when introducing environmental friendly practices. 


\subsection{Assessment of the environmental impact}

Understanding the life-cycle implications of your product early in the design process is a vital step towards an improved environmental friendly product development. Designers often lack information about specific characteristics of their components, which results in irreversible design failures. The more important is it to evaluate the life-cycle in the early phase of conceptual design.

Autodesk collaborates with Sustainable Minds brought about a way for Autodesk ${ }^{\circledR}$ Inventor ${ }^{\circledR}$ users to analyze a product's environmental impact from an exported bill of materials (BOM).

\subsubsection{Lifecycle Analysis with Inventor ${ }^{\circledR}$ and Sustainable Minds}

Sustainable Minds is a Web-based service for a comprehensive and standardized system that allows you to estimate, evaluate, compare and track the life cycle environmental and human health performance of products in an early stage of the design. Sustainable Minds can be accessed by http:/www.sustainableminds.com/.

Sustainable Minds, 2010 assesses and compares alternatives of product concepts for their life-cycle performance. The LCA is performed at any point, as early as during the concept design phase. Sustainable Minds closely follows the steps for LCA defined by the ISO 14040 standard, starting with the goal and scope definition. For the creation of the reference project, BOM data can be loaded from the CAD model. The material names in AutoCAD ${ }^{\circledR}$ Inventor ${ }^{\circledR}$ are mapped to the Sustainable Minds impact factor database.

By defining the system bill of materials (SBOM) all the materials in the product and packaging, major material processing steps in manufacturing, energy, fuel and other consumables used during the use phase, end of life scenarios, and transportation activities are specified. In this step, the user identifies what contributes the most to the overall environmental impact of the product. 


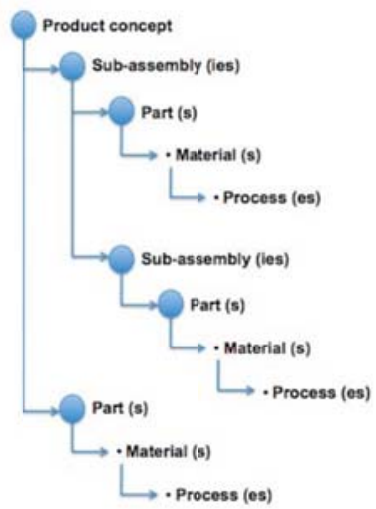

Fig. 32 System Bill of Material (SBOM) (Sustainable Minds, 2010)

The ecological performance results of product concepts with the reference are compared by viewing multiple concepts. The environmental and human health impacts of each product concept, as compared to the reference is viewed and compared. This allows you to assess alternative what-if scenarios and identify those with superior ecological performance. Figure 33 shows an example of comparing alternative design with the reference concept.

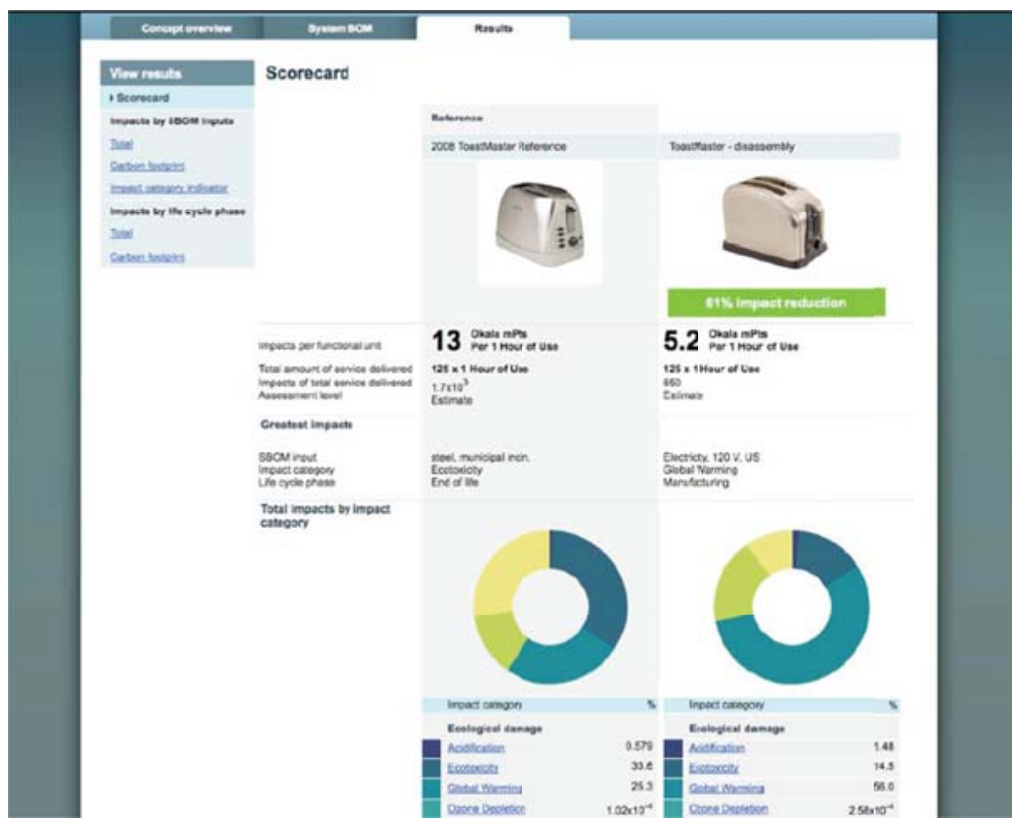

Fig. 33 System Bill of Material (Sustainable Minds, 2010) 
The scorecard allows users to gauge the new concept against the reference design to find how decisions affect the environmental impact of the design. In the example shown in Figure 33, material choices combined with component reduction through redesign have improved the environmental score.

\subsection{CAD/PLM Solution Suppliers and Sustainability Development}

Sustainability issues are becoming increasingly important to manufacturers and many of today's leading CAD/PLM solution suppliers are offering capabilities for supporting sustainability efforts. Despite that the focus on the thesis was on design and simulation solution within the Autodesk software environment, there are other software suppliers offering solutions to address environmental issues.

CAD/PLM solution providers such as Dassault Systems with Catia and Simulia, Parametric Technology with Windchill and Siemens PLM with Teamcenter rely on their PDM solutions to connect sustainable design issues with the manufacturing process. By utilizing the PDM capabilities for BOM management, the core data management tools manages the tracking, the management and reporting of compliance and related sustainability issues. PDM/PLM allows decisions made across product design and manufacturing to be documented, tracked, and made visible. (Siemens, 2010; Parametric Technology, 2010; Dassault Systems, 2010) 


\subsubsection{PTC Environmental Compliance}

PTC InSight Environmental Compliance - formerly Synapsis Technology's EMARS - is a solution for tracking and improving the environmental performance of products, parts, materials, and suppliers. PTC InSight allows manufacturers to align their product development efforts with regulatory requirements around RoHS (Restriction of Hazardous Substances), WEEE (Waste from Electrical and Electronic Equipment), REACH (Registration, Evaluation, Authorization and Restriction), as well as other directives. (Parametric Technology, 2010)

The core of PTC's InSight solution is built upon delivering a suite of capabilities to enable bill of material (BOM) analysis for environmental performance, cost, and reliability throughout the product lifecycle. PTC Insight is a Web-based service collecting and tracking status of supplier components as shown in Figure 34.

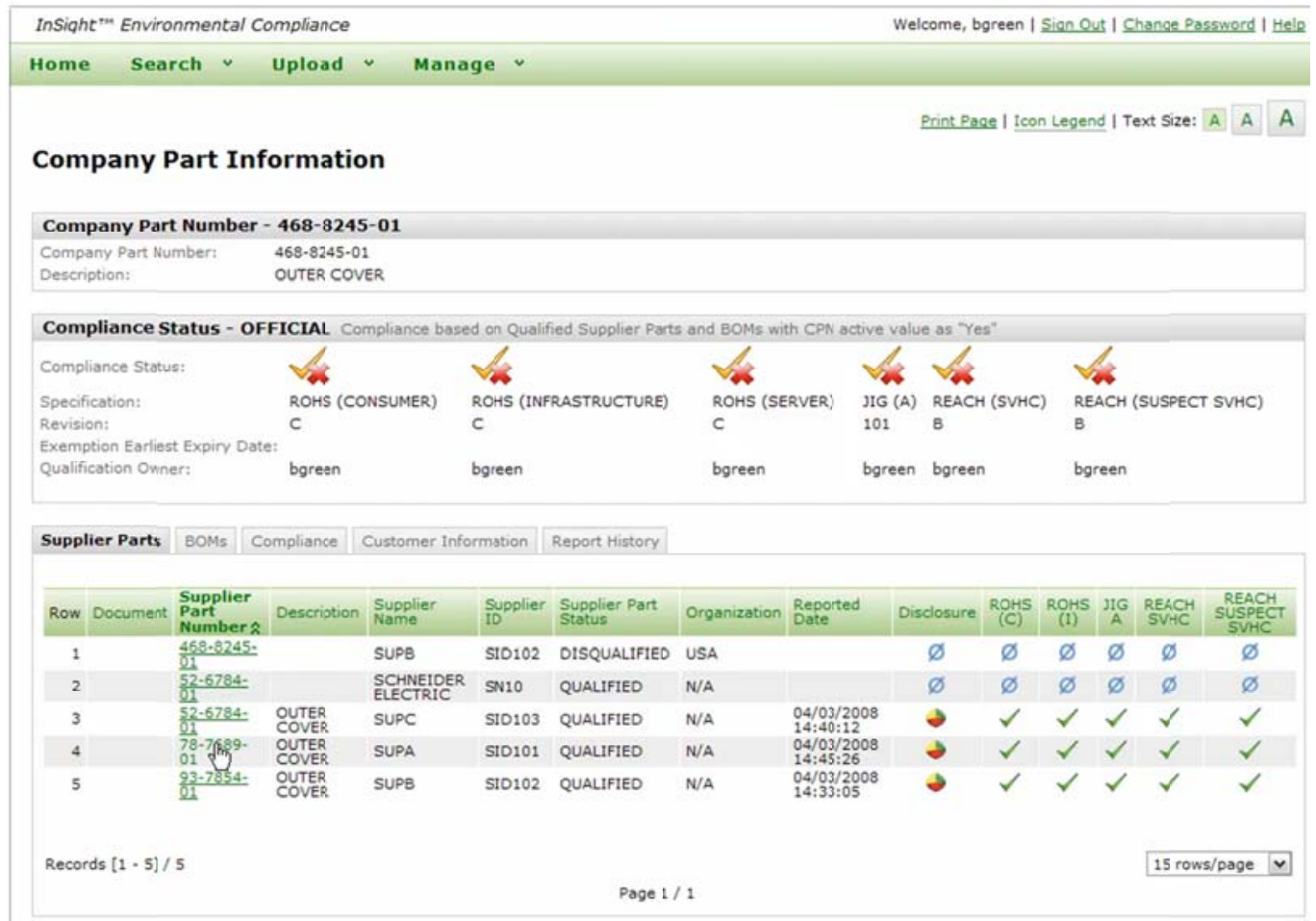

Fig. 34 PTC Insight (Parametric Technology, 2010) 


\subsubsection{Dassault Systemes Solidworks}

Dassault Systemes offers with SolidWorks Sustainability a tool to visualize the impact of the user's choices in areas such as carbon emissions, energy, air, and water throughout life-cycle stages like: materials, manufacturing, product use, and end-oflife. (Solidworks, 2010a) SolidWorks Sustainability is available as entry level version SolidWorks SustainabilityXpress free of charge and the full cost of charge version SolidWorks Sustainability. A comparison of the product features is shown in Table 5. (Solidworks,2010b)

Table 5 Comparison SolidWorks SustainibilityXpress with SolidWorks Sustainibility

\begin{tabular}{|c|c|c|}
\hline Functionality & $\begin{array}{c}\text { SolidWorks } \\
\text { SustainabilityXpress }\end{array}$ & $\begin{array}{c}\text { SolidWorks Sustain } \\
\text { ability }\end{array}$ \\
\hline Integrated into SolidWorks Interface & $\mathrm{x}$ & $x$ \\
\hline LCA of Parts & $x$ & $\mathrm{X}$ \\
\hline Find Similar Material & $x$ & $\mathrm{x}$ \\
\hline $\begin{array}{l}\text { Impact Factor Dashboard with Key } \\
\text { Categories }\end{array}$ & $\mathrm{x}$ & $\mathrm{x}$ \\
\hline Establish Baseline & $\mathrm{x}$ & $\mathrm{x}$ \\
\hline Customizable Reports & $\mathrm{x}$ & $\mathrm{x}$ \\
\hline Detailed Report for Parts & $\mathrm{x}$ & $\mathrm{x}$ \\
\hline Baseline Comparison Report & $\mathrm{x}$ & $\mathrm{x}$ \\
\hline LCA of Assemblies & & $\mathrm{X}$ \\
\hline SolidWorks Configuration Support & & $\mathrm{x}$ \\
\hline "Use Phase" Energy & & $\mathrm{x}$ \\
\hline Specify Transportation Type & & $\mathrm{x}$ \\
\hline $\begin{array}{l}\text { Report Includes BOM with } \\
\text { Best/Worst Components }\end{array}$ & & $\mathrm{x}$ \\
\hline Assembly Visualization Support & & $\mathrm{x}$ \\
\hline
\end{tabular}




\section{Results of the thesis}

Addressing environmental issues poses risks and offers opportunities to manufactures. Blus (2010) explores opportunities for sustainable product development in context of common business challenges. Related to the product development process the most important opportunities are:

\subsubsection{Potential Business Benefits}

\section{Profitability}

Using fewer material cuts costs and as a consequence, overhead and production costs are reduced by using less energy. More sustainable materials may or may not reduce costs at the front end; however it can contribute to reduce waste, emissions and pollution.

\section{Competition}

Customers are willing to pay more for safe, healthy, green products. Environmental consciousness in the product design can reveal a competitive advantage and a chance to regain market share for some types of products. Reduced operating costs with minimal energy and/or water consumption during the product life-time are likely to influence the consumer buying behavior.

\section{Compliance and Managing Risk}

Regulatory pressures will continue to increase and expand to cover materials and products whose cumulative environmental impact is deemed unacceptable (such as non-biodegradable plastic). A sustainable approach reduces the risk for noncompliance. Manufacturers are less impacted by the consequences of material shortages, energy price increase, higher fees of disposal and pollution abatement. 


\section{Market Opportunities / Growth}

Emissions reporting and mitigation plans are increasingly demanded from the supply chain partner by major corporations and public agencies. A valued third party certification can help to put products on the shortlist for companies that have implemented preferable purchasing policies for environmentally products.

\subsubsection{Adoption and Implementation of Software Tools}

Digital prototyping is defined as dealing with the complete product before it becomes real, from the conceptual design phase through the manufacturing process. There is a general tendency to provide simulation methods earlier in the design process. This is supported by the ever improving ease of use in software products.

While in the past simulation software required a lot of training to reach an expert level, today's tools allow easy access to even complex simulation and analyze. This does not mean downsizing of the required design engineering skills; it rather offers an opportunity to shift the development effort for improved innovation. 


\section{Summary and further works}

The thesis covers a broad number of concepts for improving the environmental impact of products by utilizing tools and methods involved in the design development course. Many of them allow as a side effect to improve operational efficiency and cost reduction.

Since the nature of the topic is very broad, no study on the effectiveness has been attempted. This leaves an opportunity on further research to quantify the business benefits in the context of design development.

The thesis introduces new technology products from Autodesk such as Inventor ${ }^{\circledR}$ Optimization and plastic part analysis with Project Krypton. These products are available as technology preview and can potentially contribute to accelerate the adoption of environmental design thoughts. Additionally, simulation tools utilizing cloud computing in a business environment are a relatively new technology and deserve further attention.

Furthermore, product material related considerations are seen as a major contributor to the environmental impact. Anastas and Zimmerman, (2007) mention that the inherent nature of selected material and energy inputs should be evaluated. Further research is required to overcome obstacles in the implementation of such concept in the design development process.

Last but not least, Anastas and Zimmerman, (2007) mentions, that just as every parameter in a system cannot be optimized at the same time, especially when they are interdependent, the same is true for design principles. It is important to balance the design requirements to achieve optimum solutions from cost and environmental impact point of view. 


\section{Bibliography}

Anastas, P. and Zimmerman J. (2007), Design through the 12 Principles of Green Engineering, IEEE Engineering Management Review, Vol. 35, No. 3, Third Quarter 2007

Aberdeen (2009): How SMBs Save Time and Money by Reducing Physical Prototypes with Simulation, http://www.buscom.ca/Web/Documents/MSD/ Aberdeen_WhitePaper_ReducePhysicalPrototypeswithSimulation.pdf - accessed on: 23.09 .2010

Autodesk (2010): Project Krypton Technology Preview, http://labs.autodesk.com/utilities/krypton/

- accessed on: 31.08 .2010

Autodesk (2010): Moldflow Krypton for Inventor and Solidworks, http://labs.autodesk.com/files/7101_7200/7161/file_7161.pdf - accessed on: 31.08 .2010

Autodesk (2010): Inventor Optimization Technology Preview, http://labs.autodesk.com/utilities/inventor_optimization/ - accessed on: 31.08.2010.

Autodesk (2010): Digital Prototyping: Fragen und Antworten, http://images.autodesk.com/emea_dach_main_germany/files/digital_prototypin g_-_fragen_und_antworten.pdf - accessed on: 31.08 .2010

Ashby, M. and Johnson K. (2009), Materials and Design, Second Edition, Butterworth-Heinemann, Chapter 2

Blanchard, B. and Fabrycky W. (2006), Systems Engineering and Analysis, Pearson Prentice Hall, Chapter 16

Blus, G. (2010): Manufacturing Sustainability White Paper http://images.autodesk.com/adsk/files/manufacturing_sustainability_white_pap er.pdf - accessed on: 31.08 .2010 
Cheah, L., Evans C., Bandivadekar A. \& Heywood J.(2007), Factor of Two: Halving the Fuel Consumption of New U.S. Automobiles by 2035, page 19

Dassault Systemes, (2010), Simulation Lifecycle Management, http://www.simulia.com/products/slm.html

- accessed on: 04.11.2010

Ehrlenspiel, K.; Kiewert A.;Lindemann U.; Hundal M.S.(Ed.) (2006), Cost-Efficient Design, First English Edition, Springer ASME Press, page 11-12

European Union (2010), Waste Electrical and Electronic Equipment, http://ec.europa.eu/environment//waste/weee/index_en.htm - accessed on: 02.10.2010

European Union (2010), RoHS compliance in the EU, http://www.rohs.eu/english/index.html

- accessed on: 02.10 .2010

European Union (2010), Energy efficiency, http://ec.europa.eu/energy/efficiency/ecodesign/eco_design_en.htm - accessed on: 02.10.2010

European Union (2010), REACH - Registration, Evaluation, Authorisation and Restriction of Chemicals, http://ec.europa.eu/enterprise/sectors/chemicals/reach/index_en.htm - accessed on: 02.10.2010

GMA/Deloitte (2009): Green Shopper Study, http://www.deloitte.com/assets/Dcom/UnitedStates/Local\%20Assets/Documen ts/US_CP_GMADeloitteGreenShopperStudy_2009.pdf

- accessed on: 02.10 .2010

Gordon, P. (2001), Lean and Green, Profit for your Workplace and the Environment, Berrett-Koehler Publishers, San Francisco, chapter 12

Kaltseis, F. (2010), Tools and Methods in Product Development to Reduce the Environmental Impact, IFAC SWIIS 2010 Preprint, Prishtina, page 53-57 
Lee, K. and Uehara H. (2003), Best Practices of ISO 14021: Self declared environmental claims, APEC

Parametric Technology, (2010), PTC InSight Environmental Compliance http://de.ptc.com/products/insight/environmental-compliance - accessed on: 04.11.2010

Siemens, (2010), Compliance Management, http://www.plm.automation.siemens.com/en_us/products/teamcenter/solution s_by_product/compliance_management.shtml - accessed on: 04.11.2010

Solidworks, (2010), SolidWorks Sustainability, http://www.solidworks.com/sustainability - accessed on: 04.11.2010

Solidworks (2010), SolidWorks Sustainability Feature Matrix, http://www.solidworks.com/sustainability/feature-matrix.htm - accessed on: 04.11.2010

Sustainable Minds, (2010), Sustainable Minds LCA, http://www.sustainableminds.com/product - accessed on: 02.10.2010

Willis, B. (2009), Green Intentions, CRC Press, Tailor and Francis Group, New York

Wimmer, W., Züst R. and Lee K., (2004), Ecodesign Implementation, Springer, The Netherlands

Winters, J. (2010), Compelled to be Green, IEEE Engineering Management Review, Vol. 38, No. 2, Second Quarter 2010 


\section{LIST OF FIGURES}

Fig. 1 Impact of purchasing decisions (GMA/Deloitte,2009)

Fig. 2 WEEE symbol for marking products (European Union, 2010a)

Fig. 3 Production costs in \% - according to Ehrlenspiel, et al., (2006)

Fig. 4 Inputs to the design process

- according to Ashby M. and Johnson K. (2009)

Fig. 5 The Lifecycle of a product - according to Blanchard and Fabrycky, (2006)

Fig. 6 The 4 phases of LCA (Wimmer, et al., 2004)

Fig. 7 Component/Material retirement, phase out, recycling and disposal relationship (Blanchard and Fabrycky, 2006)

Fig. 8 Energy consumption during product life-cycle, (Ashby and Johnson, 2009)

Fig. 9 Traditional design process using a physical prototype (Autodesk, 2010d)

Fig. 10 Design Process with simulation on a virtual model (Autodesk, 2010d)

Fig. 11 Shift of knowledge development progress (Autodesk, 2010d)

Fig. 12 Simulation methods (Autodesk, 2010d)

Fig. 13 Simulation Methods / Autodesk Products (Autodesk, 2010d)

Fig. 14 Calculation for Bolted Connection (Autodesk ${ }^{\circledR}$ Inventor ${ }^{\circledR}$ Software)

Fig. $\quad 15$ Mold base (Autodesk ${ }^{\circledR}$ Inventor ${ }^{\circledR}$ Tooling Software, 2010) 
Fig. $\quad 16 \quad$ Selection of plastic family (Autodesk ${ }^{\circledR}$ Moldflow ${ }^{\circledR}$ Software)

Fig. $\quad 17$ Energy usage indicator (Autodesk ${ }^{\circledR}$ Moldflow ${ }^{\circledR}$ Software)

Fig. 18 Comparison of materials (Autodesk ${ }^{\circledR}$ Moldflow ${ }^{\circledR}$ Software)

Fig. $\quad 19 \quad$ Mold fill analysis (Autodesk ${ }^{\circledR}$ Moldflow ${ }^{\circledR}$ Software)

Fig. $\quad 20 \quad$ Injection mold fill time analysis (Autodesk ${ }^{\circledR}$ Moldflow ${ }^{\circledR}$ Software)

Fig. $\quad 21 \quad$ Injection mold sink mark analysis (Autodesk ${ }^{\circledR}$ Moldflow ${ }^{\circledR}$ Software)

Fig. 22 Photorealistic defect visualization (Autodesk ${ }^{\circledR}$ Moldflow ${ }^{\circledR}$ Software)

Fig. 23 Photorealistic defect visualization with alternative material selection (Autodesk ${ }^{\circledR}$ Moldflow ${ }^{\circledR}$; Autodesk ${ }^{\circledR}$ Showcase ${ }^{\circledR}$ )

Fig. $\quad 24 \quad$ Nominal wall thickness analyze (Autodesk ${ }^{\circledR}$ Moldflow ${ }^{\circledR}$ Software)

Fig. 25 Performance indicator gauge, (Autodesk, 2010a)

Fig. $\quad 26 \quad$ Draft angle analyze (Autodesk ${ }^{\circledR}$ Inventor ${ }^{\circledR}$ Software, Project Krypton Technology Preview)

Fig. 27 Parametric model of crane gripper (Autodesk ${ }^{\circledR}$ Inventor ${ }^{\circledR}$ Software, Inventor Optimization Technology Preview)

Fig. $\quad 28$ Safety Factor Results (Autodesk ${ }^{\circledR}$ Inventor ${ }^{\circledR}$ Software, Inventor Optimization Technology Preview)

Fig. 29 Optimization results (Autodesk ${ }^{\circledR}$ Inventor ${ }^{\circledR}$ Software, Inventor Optimization Technology Preview)

Fig. $\quad 30 \quad$ Fatigue calculation for Bolted Connection (Autodesk ${ }^{\circledR}$ Inventor ${ }^{\circledR}$ Software) 
Fig. 31 Assembly documentation (Autodesk ${ }^{\circledR}$ Inventor ${ }^{\circledR}$ Publisher Software)

Fig. $32 \quad$ System Bill of Material (SBOM) (Sustainable Minds, 2010)

Fig. $33 \quad$ System Bill of Material (Sustainable Minds, 2010)

Fig. 34 PTC Insight (Parametric Technology, 2010)

\section{LIST OF TABLES}

Table 1 Eco-lables, (Wimmer, et al., 2004)

Table 2 Types of environmental labels, (Lee and Uehara, 2003)

Table 3 Parameter-Value Table for optimization

Table 4 Optimization results

Table 5 Comparison SolidWorks SustainibilityXpress with SolidWorks Sustainibility 


\section{List of abbreviations}

$\mathrm{B} 2 \mathrm{~B}-$ Business to Business

B2C - Business to Consumer

BOM - Bill of Material

CAD - Computer aided design

EU - European Union

EuP - Energy using Products

EPD - Environmental Product Declaration

ECHA - European Chemicals Agency

LCA - Life cycle assessment

PBB - Polyprominated biphenyls

PBDE - Polybrominated diphenyl ethers

PDM - Product Data Management

PLM - Product Life-cycle Management

RoHS - Reduction of Hazardous Substances

REACH - Registration, Evaluation and Authorization of Chemicals

SBOM - System Bill of Material

WEEE - Waste from Electrical and Electronic Equipment 


\section{Appendix:}

\subsection{Autodesk Product Portfolio}

\begin{tabular}{|c|c|}
\hline Product Name: & Description \\
\hline $\begin{array}{l}\text { Autodesk }{ }^{\circledR} \text { Algor }{ }^{\circledR} \text { Simulation } \\
\text { Express } 2011\end{array}$ & $\begin{array}{l}\text { Autodesk } \AA \text { Algor } \AA \text { Simulation software } \\
\text { provides a broad range of mechanical simulation } \\
\text { tools to help designers and engineers make } \\
\text { critical decisions earlier in the design process. } \\
\text { First-pass, linear static stress analysis tool to } \\
\text { validate and optimize single-part designs before } \\
\text { manufacturing. }\end{array}$ \\
\hline $\begin{array}{l}\text { Autodesk }{ }^{\circledR} \text { Algor }{ }^{\circledR} \text { Simulation } \\
2011\end{array}$ & $\begin{array}{l}\text { Design validation and optimization with a broad } \\
\text { range of mainstream engineering simulation tools } \\
\text { in a multi-CAD environment. }\end{array}$ \\
\hline $\begin{array}{l}\text { Autodesk }{ }^{\circledR} \text { Algor }{ }^{\circledR} \text { Simulation } \\
\text { CFD } 2011\end{array}$ & $\begin{array}{l}\text { All the functionality of Algor Simulation along } \\
\text { with fluid flow analysis, computational fluid } \\
\text { dynamics and mass transfer analysis. }\end{array}$ \\
\hline $\begin{array}{l}\text { Autodesk }{ }^{\circledR} \text { Algor }{ }^{\circledR} \text { Simulation } \\
\text { MES } 2011\end{array}$ & $\begin{array}{l}\text { All the functionality of Algor Simulation along } \\
\text { with nonlinear static and dynamic analysis, rigid- } \\
\text { body motion analysis, and combined stress and } \\
\text { flexible-body motion analysis. }\end{array}$ \\
\hline $\begin{array}{l}\text { Autodesk }{ }^{\circledR} \text { Algor }{ }^{\circledR} \text { Simulation } \\
\text { Professional } 2011\end{array}$ & $\begin{array}{l}\text { All the functionality of Algor Simulation, Algor } \\
\text { Simulation CFD, and Algor Simulation MES } \\
\text { along with electrostatic analysis and the ability to } \\
\text { combine analysis types for full multiphysics } \\
\text { simulations. }\end{array}$ \\
\hline
\end{tabular}




\begin{tabular}{|c|c|}
\hline Autodesk ${ }^{\circledR}$ Inventor ${ }^{\circledR}$ Publisher & $\begin{array}{l}\text { Autodesk }{ }^{\circledR} \text { Inventor }{ }^{\circledR} \text { Publisher is innovative } \\
\text { technical communications software that can help } \\
\text { manufacturers explain and differentiate their } \\
\text { products with clear, accurate, and compelling 2D } \\
\text { and interactive 3D technical documentation. }\end{array}$ \\
\hline Autodesk ${ }^{\circledR}$ Alias ${ }^{\circledR}$ Design & $\begin{array}{l}\text { The Autodesk }{ }^{\circledR} \text { Alias } \AA \text { product line }- \text { Alias } \AA \\
\text { Sketch, Alias }{ }^{\circledR} \text { Design, Alias } \AA \text { Surface and } \\
\text { Alias } \AA \text { Automotive }- \text { provides industry-leading } \\
\text { surfacing capabilities supported by best-in-class } \\
\text { sketching, modeling and visualization tools. for } \\
\text { Autodesk }{ }^{\circledR} \text { Inventor }{ }^{\circledR} \text { users. }\end{array}$ \\
\hline Autodesk $®$ Inventor ${ }^{\circledR}$ & $\begin{array}{l}\text { Autodesk }{ }^{\circledR} \text { Inventor }{ }^{\circledR} \text { mechanical design } \\
\text { software takes engineers beyond } 3 D \text { to Digital } \\
\text { Prototyping by enabling them to design, } \\
\text { visualize, and simulate products before they are } \\
\text { ever built. }\end{array}$ \\
\hline Autodesk ${ }^{\circledR}$ Showcase ${ }^{\circledR}$ & $\begin{array}{l}\text { Autodesk }{ }^{\circledR} \text { Showcase }{ }^{\circledR} 2011 \text { visual } \\
\text { communication software enables designers, } \\
\text { engineers, and marketing teams to tell the stories } \\
\text { of their designs with vividly immersive } 3 \mathrm{D} \\
\text { presentations and highly realistic renderings. }\end{array}$ \\
\hline AutoCAD ${ }^{\circledR}$ Electrical ${ }^{\circledR}$ & $\begin{array}{l}\text { AutoCAD } \AA \text { Electrical is AutoCAD } \AA \text { software } \\
\text { for controls designers, purpose-built to accelerate } \\
\text { the creation of electrical control systems by } \\
\text { automating electrical engineering tasks and } \\
\text { providing comprehensive symbol libraries. }\end{array}$ \\
\hline
\end{tabular}




\begin{tabular}{|c|c|}
\hline Factory Design Suite ${ }^{\circledR}$ & $\begin{array}{l}\text { Autodesk }{ }^{\circledR} \text { Factory Design Suite is an integrated } \\
\text { 2D/3D factory layout solution purpose-built to } \\
\text { help you make better layout decisions by creating } \\
\text { a digital prototype of your factory. }\end{array}$ \\
\hline Autodesk ${ }^{\circledR}$ Inventor ${ }^{\circledR}$ Tooling & $\begin{array}{l}\text { Autodesk }{ }^{\circledR} \text { Inventor }{ }^{\circledR} \text { Tooling software helps } \\
\text { automate key aspects of the design of injection } \\
\text { molds for plastic parts. }\end{array}$ \\
\hline Autodesk ${ }^{\circledR}$ Moldflow ${ }^{\circledR}$ & $\begin{array}{l}\text { Autodesk }{ }^{\circledR} \text { Moldflow }{ }^{\circledR} \text { Adviser injection } \\
\text { molding simulation software provides wizard- } \\
\text { based tools to help validate and optimize plastic } \\
\text { part, injection mold, and tool designs before } \\
\text { manufacturing begins. }\end{array}$ \\
\hline Autodesk $®$ Vault & $\begin{array}{l}\text { The Autodesk }{ }^{\circledR} \text { Vault product line helps } \\
\text { workgroups control project-related design data, } \\
\text { manage change processes to minimize costly } \\
\text { mistakes, and more efficiently release and revise } \\
\text { designs. }\end{array}$ \\
\hline
\end{tabular}




\subsection{Moldflow Advisor Summary Report of fill Analysis}

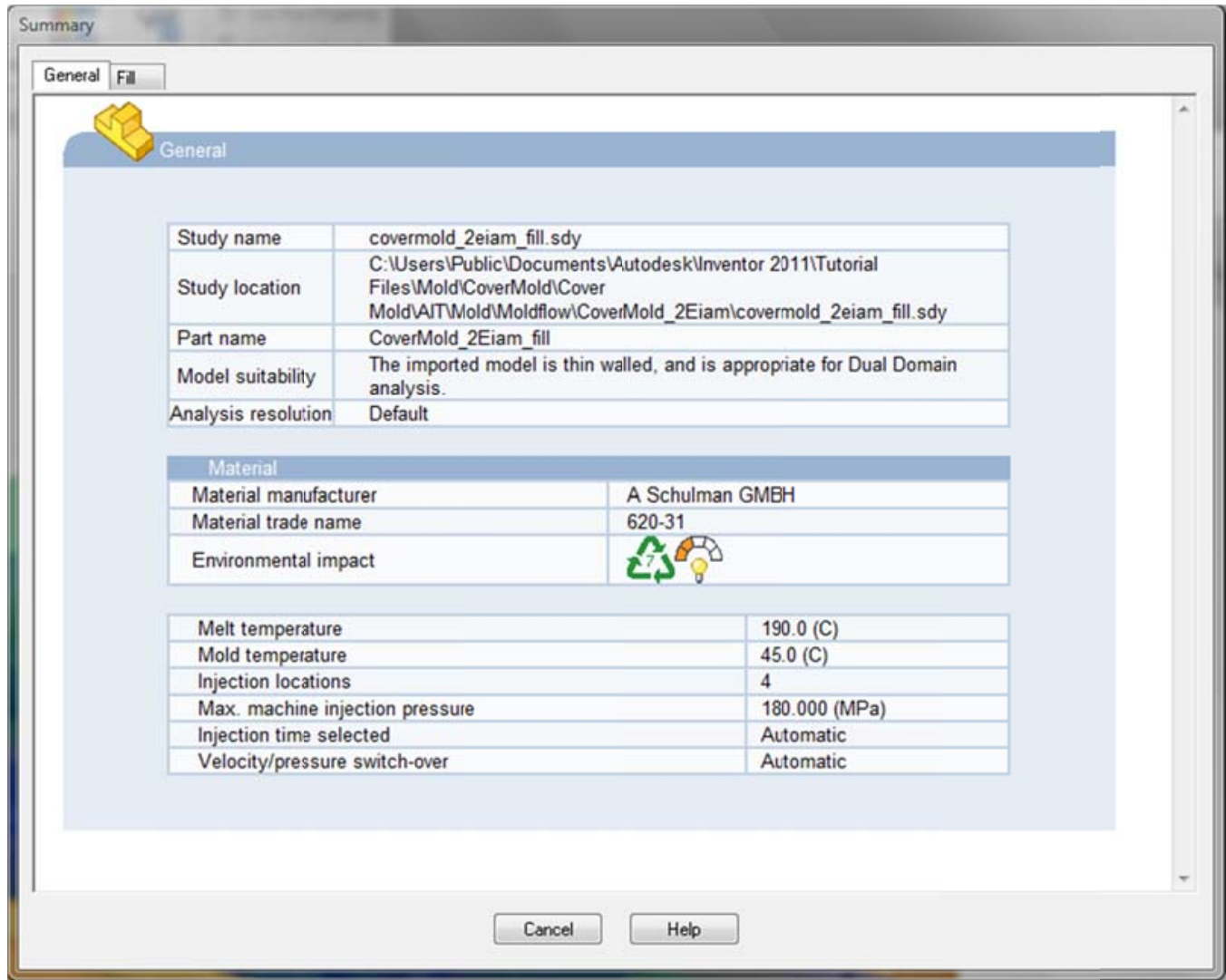




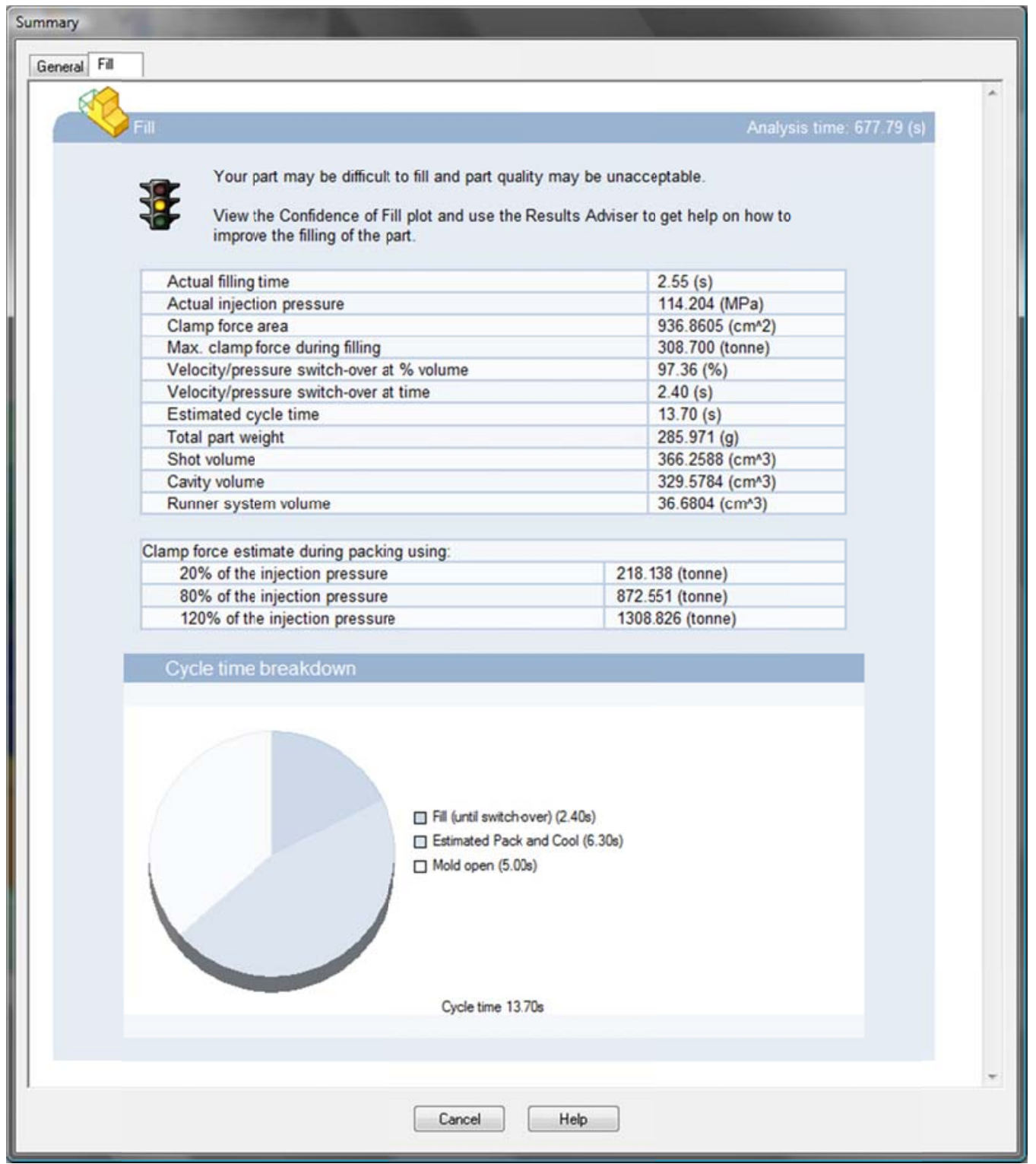

